\title{
Digital Family Life: A Systematic Review of the Impact of Parental Smartphone Use on Parent-Child Interactions
}

\author{
Barbara Knitter ${ }^{1} \&$ Martina Zemp ${ }^{1 *}$ \\ ${ }^{1}$ University of Vienna, Department of Clinical and Health Psychology, Renngasse 6-8, 1010 Vienna, Austria.
}

\begin{abstract}
Smartphone use among parents is rising sharply, as they seek connectedness with partners, friends and work during the sometimes socially disconnected times of parenthood. Since parents increasingly use smartphones while interacting with their children, there is a growing body of research about the implications of parental smartphone use for parent-child interactions. However, previous reviews have not examined whether the effects of parental smartphone use on parent-child interactions vary depending on children's age. Additionally, no systematic review has summarized the potential benefits of parents' smartphone use for parent-child interactions. Therefore, the goals of this systematic review were: (1) to explore the links between parental smartphone use and the quality of parent child-interactions in four different age groups of children; and (2) to review potential benefits of parental smartphone use for these interactions. Following PRISMA guidelines, a total of $k=21$ papers met all eligibility criteria and were included in this review. Results suggest associations between parental smartphone use and parent-child interactions across all age groups, but the foci and outcomes of the studies differed. Only a few studies have focused on the potential benefits of parental smartphone use for parent-child interactions. The review provides an overview of areas of future research to explore how smartphone use changes family interactions. Families have to find adequate ways of dealing with new technology in everyday life, which inevitably affects the nature of their daily interactions.
\end{abstract}

Keywords: parental mobile phone use, parent-child relationship, parenting, technoference, digital media
Article History

Received 4 October 2019

Revised 8 January 2020

Accepted 8 January 2020

DOI 10.24989/dp.v1i1.1809
Digital media are ubiquitous in modern societies. In $201582 \%$ of adults (25-54 years) accessed the internet via a smartphone in Europe (Eurostat, 2016). In addition, 94\% of adults use their smartphone on a daily basis for more than three hours a day in Austria (Mobile Marketing Association Austria, 2018). Interestingly, 34\% of adolescents (aged 11-17 years) stated that they think their parents use their phone too often (Saferinternet, 2019). The permanent virtual connectedness of parents has resulted in a shift from traditional face-to-face interactions towards technology-based interactions (Stern \& Messer, 2009), which inevitably affects everyday family interactions too. Similarly, the more adolescents used their smartphone, the lower they rated the overall quality of the relationship with their parents (Kildare \& Middlemiss, 2017). Hence, there might be mutual effects of family members' smartphone use: Parents as well as their children seem to be absorbed by their smartphones in everyday family life, which likely affects parent-child relations.

The phenomenon of interference and interruption of everyday face-to-face interactions through technology, in particular smartphones, has been referred to in the literature as "technoference” (McDaniel \& Coyne, 2016). Recently, parental smartphone use and the implications for parent-child interactions have received increasing scientific attention (Kildare \& Middlemiss, 2017). Parents are engaged in screen media on personal and work-related matters throughout the day, and thus likely also use smart devices during parent-child interactions (e.g. text messaging while playing with their children; Beamish, Fisher, \& Rowe, 2019). The presence of digital media devices during family quality time (e.g. meals, playtime, and bedtime) may impair the social-emotional development of children, because parental attention is shifted away from their children's needs and towards their device (McDaniel \& Radesky, 2018). Given the rise and topicality of this research area, two recent narrative reviews (Kildare \& Middlemiss, 2017; McDaniel, 2019) outlined the impact of parental technoference on parent-child interactions. However, the reviews lacked a systematic approach, included a broad range of studies (including studies focusing on mobile devices other than smartphones), and exclusively focused on the negative effects on parenting (e.g. more accidents as parents are 
distracted) as well as the negative effects on children (e.g. insecure attachment, irritated children).

The potential negative impact of technoference on parentchild relations can theoretically be explained by attachment theory (Ainsworth, 1979, Bowlby, 1969). According to attachment theory, parental sensitivity is one of the strongest predictors of high parent-child relationship quality and the children's secure attachment, which in turn, affect children's long-term social, psychological and health outcomes (e.g. Fearon, BakermansKranenburg, van IJzendoorn, Lapsley, \& Roisman, 2010). Parental sensitivity is conceptually defined as the parents' awareness of their child's needs, their accurate interpretation of those needs, and the contingent and appropriate response to those needs (Ainsworth, Blehar, Waters, \& Wall, 1978). It is well conceivable that technoference impairs parental sensitivity. That is, when parents are distracted by their smartphones, they are likely to be less attentive and responsive to their children's needs, which can negatively affect child attachment and development (Kildare \& Middlemiss, 2017).

The role of parental sensitivity for children's attachment has traditionally been examined in infancy. Especially in the first years of their lives, infants depend on their parents to survive, and with increasing mobility rely on their parents to guide them through challenges and to provide a secure base. However, albeit initially developed in infancy, attachment still has regulatory functions during middle childhood and through adolescence (Grossmann, Grossmann, Kindler, \& Zimmermann, 2008). As children grow older, they need less parental support because they are more able to handle their emotions and feelings of distress independently, have a greater capacity for self-regulation, and receive increasing social support outside the family (Zimmer-Gembeck et al., 2017). Although adolescents less frequently express their attachment needs by physical proximity in times of stress, they still seek emotional support from their parents when needed (Zimmermann, Mohr, \& Spangler, 2009). Hence, parental sensitivity is not only relevant in early childhood, but remains an important protective factor across the child's development through adolescence until young adults leave home.

Only a small number of studies have examined whether the effects of parental smartphone use on parent-child interactions vary depending on the age of the child. Moreover, no reviews have systematically investigated previous research about the impact of parental smartphone use across different developmental stages of children. This is particularly lamentable, as there is evidence that parents' use of information and communication technology increases with the age of children (Rudi, Dworkin, Walker, \& Doty, 2015). Therefore, the first goal of this systematic review is to explore the role of children's age in the link between parental smartphone use and parent-child interactions, as this allows for a more thorough understanding of the meaning of technoference for families.

In addition, the existing literature has mainly focused on the negative effects of parental smartphone use on parent-child in- teractions (McDaniel, 2019), for instance distraction of mothers while feeding their babies (Golen \& Ventura, 2015) or while at the playground with their children (Hiniker, Sobel, Suh, Sung, Lee, \& Kientz, 2015). Given the importance of awareness of this potential negative impact, it becomes evident that more research, especially longitudinal, is required to fully explore this highly relevant topic. Nevertheless, far less research has been devoted to date to investigating the possible benefits of parental smartphone use for family interactions. Recent research has begun to focus on benefits of smartphone use for children's and parents' feelings of connectedness in the family (Coyne, PadillaWalker, Fraser, Fellows, \& Day, 2014; Devitt \& Roker, 2009), but, to our knowledge, no systematic review has summarized the potential benefits of parental smartphone use for parent-child interactions. Therefore, the second goal of this review is to address this gap.

\section{The Current Review}

This systematic review summarizes studies examining a specific form of technoference, i.e. the effects of parental smartphone use on parent-child interactions, with a focus on two main research questions:

First, do the links between parental smartphone use and the quality of parent child-interactions vary across four different age groups of children (infancy, preschoolers, school-age children, and adolescents)? We hypothesize that the impact differs insofar as with younger children parental sensitivity is impaired, whilst with older children the quality of parent-child interactions and perceived parental support are affected.

Second, what are the benefits of parents' smartphone use for parent-child interactions? We expect that there are possible benefits of parental smartphone use for parent-child interactions, which have been neglected in previous research that has focused on the negative consequences of technoference for parent-child interactions.

\section{Method}

\subsection{Search Strategy}

The systematic literature search followed PRISMA guidelines (Moher, Liberati, Tetzlaff, Altman, \& the PRISMA Group 2009) and was conducted by the first author in June and July 2019. The following databases and search engines were searched for relevant literature by using a combination of key search terms in English and German (see Table 1 in the electronic supplements): Pubmed, Psychnet, Web of Science, Proquest, Ebsco, and Google Scholar. During the process of literature search, references included in previous reviews and studies were screened in terms of our eligibility criteria (see below). In addition, the existing literature/library of the research team was included as addition- 
al records $(k=27)$. The title and abstract of 4,667 total records were screened by the first author. Among them, 4,565 records were excluded because abstract analysis revealed that they were unsuitable for the current review. As a next step, duplicates $(k=$ 43) were removed. The remaining $(k=59)$ were given full consideration by a thorough full text analysis. In uncertain cases, the first author consulted the second author and discussed if the article should be included. Ultimately, a total of 21 records met all eligibility criteria and were included in this review (asterisk $\left.{ }^{*}\right]$ in the reference list). The flow chart describes all stages of the selection process (see Figure 1).

\subsection{Inclusion Criteria}

To be included in the review, the studies had to meet the following criteria: (1) examining parental smartphone use during a parent-child interaction, defined as any form of spending time together (eating, playtime, being in the same room); (2) using methods to assess the quality of the parent-child interactions (e.g. interaction quality, parental sensitivity etc.); and (3) the age of the children had to be between 0 and 18 years. To address our first research question (i.e. whether the effects of parental smartphone use vary across children's age), we predefined four age groups to categorize the different stages of child development:

- Age group 1: infants and babies (0-3 years);

- Age group 2: toddlers and preschool children (4-6 years);

- Age group 3: school-age children (7-10 years);

- Age group 4: adolescents (11-18 years).

\subsection{Exclusion Criteria}

Excluded were: (1) theoretical papers or book chapters and narrative reviews (not original research); (2) intervention studies aimed at improving parental media use, as these do not reflect

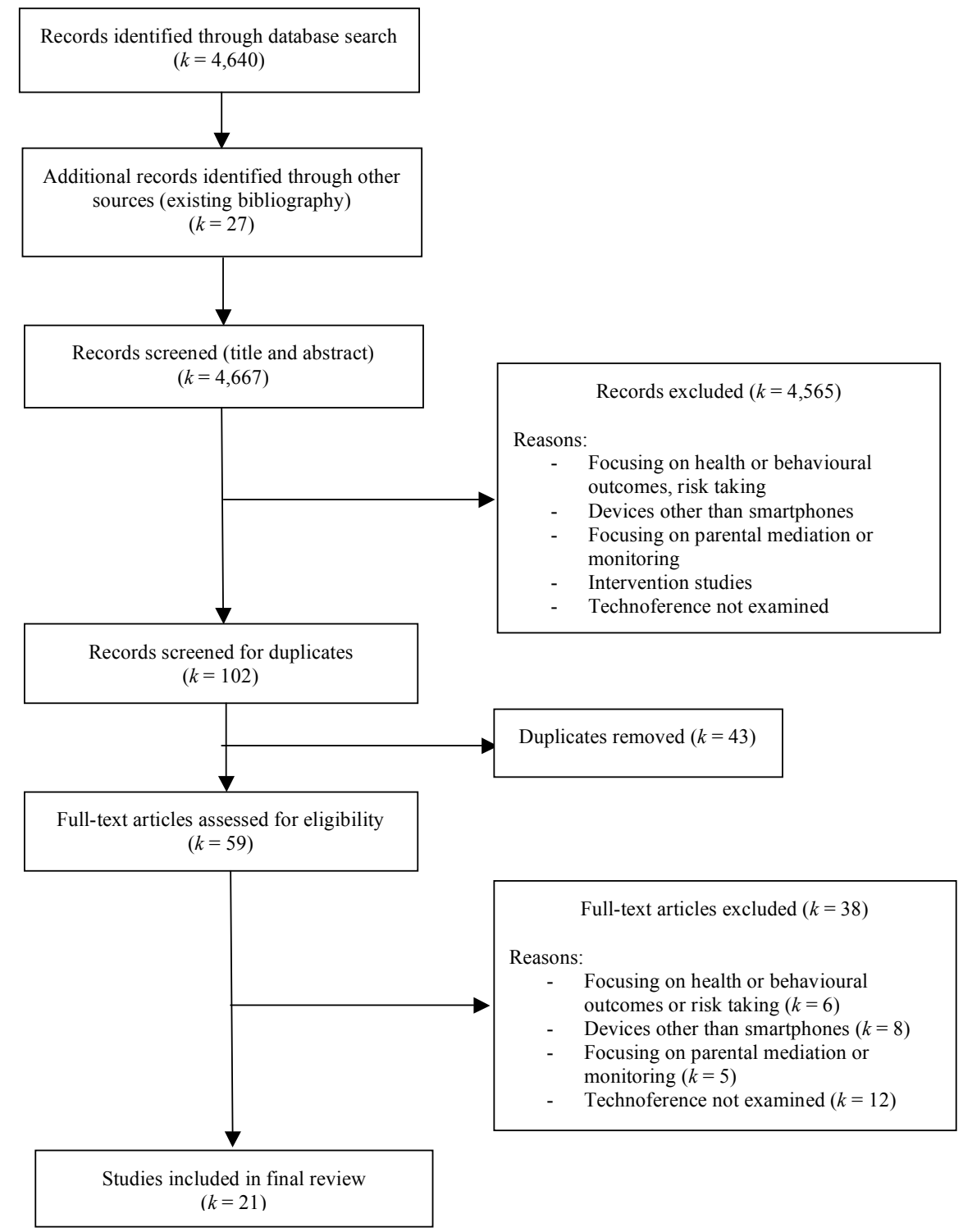

Figure 1. Flow Chart of Literature Search. 
the parental smartphone use in the natural family context; (3) studies focusing on outcomes other than parent-child interactions (e.g. internet addiction, obesity, ADHD, behavioral problems, school performance); (4) studies exclusively focusing on digital media other than smartphones; and (5) studies focusing on parental mediation and monitoring, parenting, child rearing, media competency, or pedagogy.

\subsection{Quality Assessment}

We assessed the quality of the included studies using the Mixed Methods Appraisal Tool (MMAT; Hong et al., 2018). First, the first author categorized the study designs into qualitative $(k=2)$, quantitative non-randomized $(k=2)$, quantitative descriptive $(k=11)$, and mixed methods $(k=7)$ applying the MMAT study design categories. Subsequently, the first author assessed the quality of the studies based on two general quality criteria and five design-specific quality criteria according to the MMAT. A detailed overview of the quality assessment can be found in Table 2 (see electronic supplements).

\subsection{Description of Literature}

A total of 21 records met all eligibility criteria and were analyzed for this review. Notably, one paper (Kushlev \& Dunn, 2019) included two separate studies, which were counted as one publication (hereinafter referred to as Kushlev \& Dunn, 2019 (Study 1) or Kushlev \& Dunn, 2019 (Study 2)). The 21 studies included scientific peer-reviewed publications $(k=12)$, post-graduate dissertations or Master's theses $(k=7)$, and conference papers $(k=2)$. Among them, 14 studies used survey, self-report or interview data, 6 included observational data, and 5 were based on a (quasi-)experimental design (some studies used mixed methods combining different designs). The sample sizes varied greatly between $N=12$ participants in in-depth interviews (Johnson, 2017) and $N=3.000$ participants in an online survey (Nelson, 2016). Most of the studies $(k=17)$ were conducted in North America (USA, Canada), two in European countries, one in Australia, and one in Asia (China) in urban or suburban regions. The studies were published between 2007 and 2019 inclusive.

Eight $(k=8)$ studies were unambiguously classifiable to our age groups given the mean and range of the children's age were within the predefined age ranges (Abels, Vanden Abeele, van Telgen, \& van Meijl, 2018; Blackmann, 2015; Golen \& Ventura, 2015; Kushlev \& Dunn, 2019 (Study 1); Lanette, 2018; Myruski et al., 2018; Stupica, 2016; Ventura \& Teitelbaum, 2017). Ten $(k=10)$ studies reported a broad age range that overlapped with two or more of our selected age groups (Ante-Contreras, 2016; Chen, Zhou, \& Han 2017; Kellershohn, Walley, West, \& Vriesekoop, 2018; Khourochvili, 2017; Mangan, Leavy, \& Jancey, 2018; Nelson, 2016; Palen \& Hughes, 2007; Radesky et al.,
2018; Radesky et al., 2015; Stockdale, Coyne, \& Padilla-Walker, 2018). In these cases, we always used the lower bound of the reported age range to classify the study (e.g. a study reporting the age range of 5-18 years was assigned to the second age group of 4-6 years). In sum, four $(k=4)$ studies were not classifiable $(\mathrm{n} / \mathrm{a})$, because age range was not specified (e.g. $<18$ years) or not reported at all (Hiniker et al., 2015; Johnson, 2017; Kushlev \& Dunn, 2019 (Study 2); Oduor et al., 2016).

\section{Results}

We first report results separated by each selected age group (research question 1), and second report results on the potential benefits of parental smartphone use as derived from the review (research question 2). Characteristics of and detailed information on the final set of studies are summarized in Table 3 (see electronic supplements).

\subsection{Age Group 1: Infants and Babies (0-3 Years)}

We included $k=11$ studies in this section (Abels et al., 2018; Ante-Contreras, 2016; Chen et al., 2017; Golen \& Ventura, 2015; Kellershohn et al., 2018; Mangan et al., 2018; Myruski et al., 2018; Palen \& Hughes, 2007; Radesky et al., 2018; Radesky et al., 2015; Ventura \& Teitelbaum, 2017). In this age group, a predominant line of research has focused on technoference during mealtime, a special instance of family quality time. Specifically, in an observational study (Radesky et al., 2015) one third of low-income parents who glanced at least once at their phone during eating showed fewer verbal and non-verbal interactions and displayed less engagement to try new things with their children. However, the parental phone use was not linked to parenting style or overreacting when kids sought attention. Another study found that mothers with a greater smartphone use during mealtime perceived their children as more difficult and they scored lower on a caregiving sensitivity index, as assessed by a semi-structured interview (Radesky et al., 2018). The reasons for parental smartphone use in this age group were habit, disengagement, or boredom (Radesky et al., 2018). During mealtime, $25 \%$ of adults who used their smartphone used it to take pictures (Kellershohn et al., 2018). In addition, it was observed that some parents used their phones when they were eating with their children in a restaurant, but most of them $(70 \%)$ used it when their children were at the restaurant's indoor play area. In a diary study, mothers were asked to report distractions during feeding ("what else, if anything, they were doing while feeding their infants"). A quarter (26\%) reported at least one technological distraction, $18 \%$ a non-technological distraction, and $56 \%$ no distraction at all during the feeding interaction. Higher amounts of technoference correlated with an unstructured maternal feeding style (e.g. feeding in front of the TV), mothers not noticing 
when children have eaten enough, as well as thinking children had a greater appetite (Ventura \& Teitelbaum, 2017).

An observational study found a positive correlation between frequency of parental smartphone use and child age (age range of children $=0-5$ years), suggesting parental phone involvement was higher when children were older (Abels et al., 2018).The authors found that parental phone involvement was negatively associated with parental responsiveness and children had to increase their effort in gaining their parents' attention. A similar finding was reported when parents were unavailable due to smartphone use; children's bids for attention increased, with a greater negative effect on children with emotion regulation difficulties (Myruski et al., 2018).

Looking at parenting styles, a study found that the amount of hours spent by parents on social media accessed with smartphones was related to an authoritarian parenting style (AnteContreras, 2016). Yet, this contradicts another finding in a Chinese sample showing a negative correlation between smartphone use and an authoritarian parenting style (Chen et al., 2017).

With regard to the intensity and duration of smartphone use during parent-child interactions, an observational study found that the majority of parents used their smartphones for less than 5 minutes for typing, talking or camera during a $20 \mathrm{~min}$ observation period at a playground. In $4 \%$ of the total observation time, parents ignored children's bids for attention or disengaged from ongoing parent-child interactions due to phone use. The results showed a contrast between observational data and parents' self-reports, as most parents stated in the interview following the observation that they would find it inappropriate to use their phone during child supervision at the playground.

\subsection{Age Group 2: Toddlers and Preschool Children (4-6 Years)}

We included $k=4$ studies in this section (Khourochvili, 2017; Kushlev \& Dunn, 2019 (Study 1); Nelson, 2016; Stupica, 2016). Khourochvili (2017) reported that the frequency of parental smartphone use was negatively linked with parents' sensitivity towards their infants. Results further suggested that parents with a positive attitude towards smartphones were more competent to decide when it is appropriate to use the devices and when interaction with their child is more important. The findings of a study analyzing parental beliefs and behavior showed that smartphones can possibly have inadvertent, negative consequences on parent-child interactions during family mealtime, as parental happiness and feeling of connection decreased when a smartphone was present on the table (Nelson, 2016). In an experimental study (Stupica, 2016) parental availability and responsiveness were experimentally manipulated to determine the effects on children's athletic performance. Children were asked to run as fast as possible around a softball diamond twice: once while parents were available and responsive and once while par- ents were unavailable and unresponsive (instruction for parents: "Fully engage your attention in your mobile phone becoming completely engrossed in it while standing in the box turned toward your child. Do not respond to any of your child's attempts to initiate interaction"). Children ran about three seconds faster and were $17 \%$ less likely to trip, fall, or false start in the parental available and responsive condition. Furthermore, children ran faster as their parents' availability increased.

In an experimental approach (Kushlev \& Dunn, 2019 (Study 1)), participants were asked to maximize ("high use") or minimize their phone use ("low use") during a visit to a children's museum. The manipulation was assessed through use of a parental self-report which indicated whether during the experiment they used their phone more often ("high use") or less often ("low use") than they would normally do. The "high-use" parents reported having a lower quality of attention towards their children and feeling less connected to them compared to the "low use" parents.

\subsection{Age Group 3: School-Age Children (7-10 Years)}

In this age group, we included $k=1$ study (Blackmann, 2015). The study examined the association between parental screen time, screen distraction, and parental characteristics (beliefs and demographics). It was found that parental screen time was correlated with screen distraction and this link was mediated by income and education. Further, screen distraction was negatively linked with parental responsivity towards their children's needs (Blackmann, 2015).

\subsection{Age Group 4: Adolescents (11-18 Years)}

In this age group, $k=2$ studies were included (Lanette, 2018; Stockdale et al., 2018). According to Stockdale et al. (2018), $12 \%$ of adolescents stated that their parents, when distracted by their smartphone, were "quite a bit" or "a great deal" ignoring them, and $11 \%$ said they had difficulties in getting their parents' attention in those situations. Results showed that parental technoference had an influence on adolescents' perceived feeling of parental warmth, which in turn was linked to increased levels of anxiety, depression, cyberbullying, and, unexpectedly, higher levels of prosocial behavior toward family members and strangers. The findings by Lanette (2018) indicated that the mere presence of smartphones had only minimal effects on parental listening qualities and meaningful parent-teen conversations were still possible. Nevertheless, parents and teens felt more distant when a smartphone was present during the conversation.

\subsection{Studies not Assignable to the Age Groups}

In sum, $k=4$ studies were not assignable to our predefined age groups, because the age range was not specified or not re- 
ported (Hiniker et al., 2015; Johnson, 2017; Kushlev \& Dunn, 2019 (Study 2); Oduor et al., 2016). Observing parents at the playground with their school-age children revealed that almost two-thirds of parents used their smartphone less than $5 \%$ of their time at the playground (Hiniker et al., 2015). Participants reported being driven by guilt to reduce their smartphone use, but felt incapable of doing so. To counter this, they developed strategies to use their smartphones when the children were safe and occupied (e.g. in bucket swings), or avoided the phone (e.g. locking the phone in the car) in general when with their children. The reported reasons for smartphone use were twice as often related to childcare (such as checking the time, coordinating with others, and taking pictures) as to parent-related activities (such as socializing, work or entertainment). In 32 cases in which parents were observed using their smartphone and children were bidding for parental attention, $56 \%$ of the parents did not at all respond to their children's bids for attention (not even looking away from the phone). In contrast, when children were bidding for their parents' attention without smartphone distraction, only $11 \%$ of parents did not respond. Notably however, the overall observation period was dominated by parent-child interactions and parents watching their children (Hiniker et al., 2015).The effects on parental attention quality were confirmed by a diary study (Kushlev \& Dunn, 2019 (Study 2)), where parents reported that two thirds of parent-child interactions included a smartphone. In the study by Oduor et al. (2016), parents reported that their smartphone use affected parenting and made them feel socially disconnected from their children. Moreover, participants reported feelings of guilt and that they wanted to change their smartphone behavior (Oduor et al., 2016). In addition, adolescents reported that they made parents aware of their disconnection with the real world and that they missed face-toface connection with their parents (Johnson, 2017).

\subsection{Potential Benefits of Parental Smartphone Use}

Coming to our second research question, we found that $k=8$ studies reported any form of benefit of parental smartphone use for parent-child interactions (Chen et al., 2017; Golen \& Ventura, 2015; Hiniker et al., 2015; Kellershohn et al., 2018; Kushlev \& Dunn, 2019 (Study 1); Mangan et al., 2018; Oduor et al., 2016; Palen \& Hughes, 2007). One direct advantage of parental smartphone use for parents reported was entertainment and moments of relaxation while infants were feeding from their bottle (Golen \& Ventura, 2015). Furthermore, parents reported the benefit of getting parenting support (e.g. accessing information on parenting via the internet or social media), as well as connecting with their children (Mangan et al., 2018). Chinese mothers reported benefitting from smartphones in terms of connecting with their children on a new level, combining fun, entertainment and learning together, as well as in relation to connecting with other parents. Moreover, smartphone use was associated with lower levels of authoritarian parenting, presumably as smartphones modern- ize parenting and enable those parents to break away from their own traditional strict Chinese upbringing (Chen et al., 2017).

Other findings suggest that when parents used their phones to enrich the interaction (e.g. seeking information about a topic they were talking about), they reported higher levels of social connectedness (Kushlev \& Dunn, 2019 (Study 1)). Similarly, parental smartphone use was perceived as helpful and beneficial when its purpose was useful to family life (e.g. looking up a location, interacting with distant family members; Oduor et al., 2016). Similarly, in interviews parents and caregivers reported positive effects including the use of smartphones as a tool to organize family life (Mangan et al., 2018) and to take pictures (Chen et al., 2017; Hiniker et al., 2015; Kellershohn et al., 2018). Benefits were particularly identified in relation to interaction with distant family members and friends, seeking social support, or feelings of safety in case of emergency (Mangan et al., 2018). Smartphones were also seen by some working parents as a beneficial way of "bringing home to work", in the event they needed to be reached in emergencies (Palen \& Hughes, 2007).

\section{Discussion}

The aims of this systematic review were: (1) to explore the links between parental smartphone use and the quality of parent child-interactions in four different age groups of children; and (2) to review potential benefits of parental smartphone use for these interactions. Regarding our first hypothesis, findings suggest that parental smartphone use was related with the quality of parent-child interactions across all age groups. Specifically, previous research found reduced parental attention and responsiveness towards their children, impaired quality of parent-child interactions or relationships, and decreases in perceived parental warmth associated with parental smartphone use. These are important findings given the omnipresence of smartphones nowadays. That said, the overall amount of parental smartphone use during the various observed parent-child interaction time intervals varied between studies, e.g. 59\% of parents used device $<5 \%$ (Hiniker et al., 2015) versus $76 \%$ of parents for over $80 \%$ of observation time (Mangan et al., 2018). This might depend on overall observation time (total time of stay at playground versus first 20 minutes) and observation frame could make a difference, as the initial minutes at the playground may typically be used to organize family life or to take a rest before playing with children again.

The foci and outcomes of the studies differed between the selected age groups. As expected, while studies of younger children predominantly examined indicators of parental sensitivity as the main outcomes, research investigating older children primarily focused on indicators of the parent-child relationship quality (such as feelings of connectedness). Concerning the reasons for smartphone use in the presence of children, parents with younger kids often reported using their phone to connect with others or out of boredom. As rearing infants and toddlers is one of the most emotionally and physically challenging tasks (Nelson, Kushlev, \& 
Lyubomirsky, 2014), the need of parents to "go online" at times seems understandable. Using the smartphone might serve as a tool for parents to recharge their batteries, while being "off duty". With older kids, parents stated that they use the phone more often in child-related contexts (e.g. contacting teacher) and the findings on the impact on parent-child interactions appear inconsistent.

Overall, various facets of parent-child interactions have been examined. Among them, mealtime situations were a predominant focus. Parents primarily used their phones when children were not at the table or when children were otherwise occupied. Observations of parents and children during mealtime in a restaurant without technology present revealed that these situations were usually of short duration, including only a few interactions (Kellershohn et al., 2018). Findings suggest that daily meals are a very important contributor to parental well-being and happiness, even in the presence of smartphones (Nelson, 2016). Hence, mealtime appears to be a special quality time for parents in everyday family life. Important to note with regard to family quality time is that it is a critical question who defines which moments belong to quality time. For example, adolescents perceived reduced parental warmth when parents were distracted during a time adolescents themselves defined as quality time, but the parents may not have been aware of this. The definition of quality time is always in the eye of the beholder. Therefore, setting rules for smartphone use during parent-child interactions to safeguard quality time in the family requires consideration of the different family members' perspectives.

Taken together, we can conclude from the current review that the context of the parents' smartphone use matters. Important contextual factors include frequency and duration of use, reasons for use, timing (quality time vs. arbitrary moments), and parents' attitudes towards smartphones. A frequent interpretation of the present findings is that smartphones are not the cause of parent-child interaction difficulties per se, but rather an extended arm of underlying relationship issues already present in analogue (offline) interactions (Radesky et al., 2018). In a similar vein, Abels et al. (2018) concluded that the impact of parental smartphone use could be associated with underlying parental unresponsiveness, rather than with the phone use itself. We deem it necessary to pursue this hypothesis in future research, because new technology is often discussed as an uncontrollable factor invading family life. If further investigations replicate that technoference can be regarded as a reflection of general parentchild relationship patterns, beyond digital media, it would have important practical implications in terms of preventing or reducing negative spillover of parental smartphone use on parentchild interactions.

Within our second research question, we reviewed potential benefits of parental smartphone use for parent-child interactions. In general, the benefits were mostly perceived when parents were relaxed and enjoying themselves, for example when being entertained, connecting with others, or gaining support from digital interactions. These advantages can indirectly be regarded as beneficial for parent-child interactions. Collectively, strikingly few studies have examined potential benefits of parental smartphone use. This confirms our hypothesis that this focus has been neglected in previous research when compared to the volume of studies on the negative consequences of technoference.

Against this backdrop, it is desirable that more scientific attention is devoted to comprehensively assessing possible positive effects of parental smartphone use on parent-child interactions. For instance, little is known about using smartphones to stay in contact with children when they leave their homes, to care for their relationship via online channels, or to connect on a level that children and adolescents increasingly use with peers. Such an approach would help us gain an adequate awareness in parents and professionals working with families to address this pertinent topic in an appropriate, dispassionate fashion.

\subsection{Limitations}

Some limitations of the reviewed studies merit consideration. First, given the high heterogeneity of measures and methods, comparability of studies was sometimes difficult to assess. In particular, the term smartphone was not used in all studies. The studies used different terms such as mobile phone or mobile device and it was sometimes unclear if they were referring to online or offline activities. We decided to use smartphone as an overall term, as currently $94 \%$ of adults use their smartphones daily. Second, some studies did not provide information about specific age ranges of children, which made it difficult (a) to categorize the studies into the a priori defined age groups, and (b) to examine differential effects between those age groups. Future studies should be more precise when reporting the age of the children, as well as analyze the impact of technoference in relation to children's age in a more systematic way. Third, the majority of studies were cross-sectional and only a few controlled for a baseline measure of the parent-child interaction or relationship quality. Furthermore, this field lacks experimental studies in particular. These issues make deducing causality impossible and we thus cannot draw definitive conclusions about whether parental smartphone use impairs parent-child interactions. Fourth, this review did not systematically account for potential moderators in the link between parental smartphone use and parent-child interactions. Looking at parental characteristics, the influence of gender, ethnicity and/or other cultural factors, income, and education level i.a. remains unclear and future studies should investigate these potential confounding factors more carefully. Additionally, almost no study considered additional forms of media use in parents (TV, computer etc.) as well as children's media use, which could possibly amplify the effects. Moreover, smartphones are not the only mode of parental distraction, as several studies also assessed other distractions (siblings, preparing dinner, etc.; Kushlev \& Dunn, 2019). Future experimental studies might address whether technoference has different effects on parent-child interactions than non-technological distraction. 


\subsection{Conclusion and Future Directions}

With these caveats in mind, the current findings add to our understanding about the impact of parental smartphone use on parent-child interactions. Given that this research field is still in its infancy, more knowledge is needed about: (1) parental user habits and absorption level; (2) underlying mechanisms and moderating factors; (3) parental and child attitudes towards smartphone use in the family setting; and (4) potential benefits for family interactions and relationships. Families have to find adequate ways of dealing with new technology in everyday life, which inevitably affects the nature of their daily interactions. It is a new form of navigation through close relationships in analogue and digital spheres. Therefore, we think that it is high time to examine more thoroughly how parents can model for their kids a well-balanced and relationship-compatible handling of smartphones in day-to-day life.

\section{References}

* Studies included in the systematic review are marked with an asterisk $(k=21)$

*Abels, M., Vanden Abeele, M., van Telgen, T., \& van Meijl, H. (2018). Nod, nod, ignore: An exploratory observational study on the relation between parental mobile media use and parental responsiveness towards young children. In E. M. Luef \& M. M. Marin (Eds.), The talking species: Perspectives on the evolutionary, neuronal, and cultural foundations of language (pp. 195-228). Graz: Uni-Press Verlag.

Ainsworth, M. D. S. (1979). Infant-mother attachment. The American. Psychologist, 34(10), 932-937. https://doi.org/10.1037/0003066X.34.10.932

Ainsworth, M. D. S., Blehar, M. C., Waters, E., \& Wall, S. (1978). Patterns of attachment. A psychological study of the strange situation. Hillsdale: NJ Erlbaum.

Anderson, D. R., \& Hanson, K. G. (2017). Screen media and parentchild interactions. In R. Barr \& D. N. Linebarger (Eds.), Media exposure during infancy and early childhood: The effects of content and context on learning and development (pp. 173-194). Switzerland: Springer International Publishing.

Ante-Contreras, D. (2016). Distracted parenting: How social media affects parent-child attachment. Dissertation, California State University, San Bernardino. Retrieved from https://scholarworks.lib.csusb. edu/etd/292

Beamish, N., Fisher, J., \& Rowe, H. (2019). Parents' use of mobile computing devices, caregiving and the social and emotional development of children: a systematic review of the evidence. Australasian Psychiatry, 27(2), 132-143. https://doi.org/10.1177/1039856218789764

*Blackmann, A. (2015). Screen time for parents and caregivers: Parental screen distraction and parenting perceptions and beliefs. Dissertation, Pace University, New York City. Retrieved from https://digitalcommons.pace.edu/dissertations/AAI3664563/

Bowlby, J. (1969). Attachment: Attachment and loss (Bd. 1.). New York: Basic Books.

Carvalho, J., Francisco, R., \& Relvas, A. P. (2015). Family functioning and information and communication technologies: How do they re- late? A literature review. Computers in Human Behavior, 45, 99-108. https://doi.org/10.1016/j.chb.2014.11.037

${ }^{*}$ Chen, H., Zhou, L., \& Han, S. (2017). Protest and protect. Journal of Asian Pacific Communication, 27(1), 99-120. https://doi. org/10.1075/japc.27.1.06che

Coyne, S. M., Padilla-Walker, L. M., Fraser, A. M., Fellows, K., \& Day, R. D. (2014). "Media time = Family time": Positive media use in families with adolescents. Journal of Adolescent Research, 29(5), 663-688. https://doi.org/10.1177/0743558414538316

Devitt, K., \& Roker, D. (2009). The role of mobile phones in family communication. Children \& Society, 23(3), 189-202. https://doi. org/10.1111/j.1099-0860.2008.00166.x

Eurostat. (2016). Digital economy and society statistics - households and individuals - statistics explained. Retrieved from https://ec.europa. eu/eurostat/statistics-explained/index.php/Digital_economy_and_ society_statistics_-_households_and_individuals\#Internet_usage

Fearon, R. P., Bakermans-Kranenburg, M. J., van IJzendoorn, M. H., Lapsley, A.-M., \& Roisman, G. I. (2010). The significance of insecure attachment and disorganization in the development of children's externalizing behavior: a meta-analytic study. Child Development, 81, 435-456. https://doi.org/10.1111/j.1467-8624.2009.01405.x

${ }^{*}$ Golen, R. P., \& Ventura, A. K. (2015). What are mothers doing while bottle-feeding their infants? Exploring the prevalence of maternal distraction during bottle-feeding interactions. Early Human Development, 91(12), 787-791. https://doi.org/10.1016/j.earlhumdev. 2015.09.006

Grossmann, K. E., Grossmann, K., Kindler, H. \& Zimmermann, P. (2008). A wider view of attachment and exploration: The influence of mothers and fathers on the development of psychological security from infancy to young adulthood. In J. Cassidy \& P. R. Shaver (Eds.), Handbook of attachment: Theory, research, and clinical applications (pp. 857-879). New York: Guilford.

${ }^{\star}$ Hiniker, A., Sobel, K., Suh, H., Sung, Y.-C., Lee, C. P., \& Kientz, J. A. (2015). Texting while parenting: How adults use mobile phones while caring for children at the playground. Proceedings of the $33 \mathrm{rd}$ Annual ACM Conference on Human Factors in Computing Systems, 727-736. https://doi.org/10.1145/2702123.2702199

Hong, Q. N., Pluye, P., Fàbregues, S., Bartlett, G., Boardman, F., Cargo, M., ...Vedel, I. (2019). Improving the content validity of the Mixed Methods Appraisal Tool (MMAT): A modified e-Delphi study. Journal of Clinical Epidemiology, 111, 49-59.e1. https://doi.org/10.1016/j. jclinepi.2019.03.008

Johnson, D. (2017). Parents' perceptions of smartphone use and parenting practices. UNLV Theses, Dissertations, Professional Papers, and Capstones. Retrieved from https://digitalscholarship.unlv.edu/thesesdissertations/3141

${ }^{\star}$ Kellershohn, J., Walley, K., West, B., \& Vriesekoop, F. (2018). Young consumers in fast food restaurants: technology, toys and family time. Young Consumers, 19(1), 105-118. https://doi.org/10.1108/YC-082017-00731

${ }^{\star}$ Khourochvili, M. (2017). Technology and caregiver-child interaction: The effects of parental mobile device use on infants. Disseration, York University Toronto. Retrieved from https://yorkspace.library.yorku. $\mathrm{ca} / \mathrm{xmlui} / \mathrm{handle} / 10315 / 34309$

Kildare, C. A., \& Middlemiss, W. (2017). Impact of parents mobile device use on parent-child interaction: A literature review. Computers in Human Behavior, 75, 579-593. https://doi.org/10.1016/j. chb.2017.06.003 
${ }^{\star}$ Kushlev, K., \& Dunn, E. W. (2019). Smartphones distract parents from cultivating feelings of connection when spending time with their children. Journal of Social and Personal Relationships, 36(6), 16191639. https://doi.org/10.1177/0265407518769387

${ }^{*}$ Lanette, S. (2018). The mere presence of mobile phones during parentteen interactions. Dissertation, University of California. Retrieved from https://escholarship.org/uc/item/1j709942

${ }^{*}$ Mangan, E., Leavy, J. E., \& Jancey, J. (2018). Mobile device use when caring for children 0-5 years: A naturalistic playground study. Health Promotion Journal of Australia, 29(3), 337-343. https://doi. org/10.1002/hpja.38

McDaniel, B. T. (2019). Parent distraction with phones, reasons for use, and impacts on parenting and child outcomes: A review of the emerging research. Human Behavior and Emerging Technologies, 1(2), 72-80. https://doi.org/10.1002/hbe2.139

McDaniel, B. T., \& Coyne, S. M. (2016). Technology interference in the parenting of young children: Implications for mothers' perceptions of coparenting. The Social Science Journal, 53(4), 435-443. https:// doi.org/10.1016/j.soscij.2016.04.010

McDaniel, B. T., \& Radesky, J. S. (2018). Technoference: longitudinal associations between parent technology use, parenting stress, and child behavior problems. Pediatric Research, 84(2), 210-218. https:// doi.org/10.1038/s41390-018-0052-6

Mobile Marketing Association Austria (2018). Mobile communication report 2018. Retrieved from https://www.mmaaustria.at/

Moher, D., Liberati, A., Tetzlaff, J., Altman, D. G., \& the PRISMA Group (2009). Preferred reporting items for systematic reviews and metaanalyses: the PRISMA statement. PLoS Medicine, 6(7): e1000097. https://doi.org/10.1371/journal.pmed.1000097

*Myruski, S., Gulyayeva, O., Birk, S., Pérez-Edgar, K., Buss, K. A., \& Dennis-Tiwary, T. A. (2018). Digital disruption? Maternal mobile device use is related to infant social-emotional functioning. Developmental Science, 21(4), e12610. https://doi.org/10.1111/desc.12610

*Nelson, J. J. (2016). Are we happy now? Assessing the role of electronic technology in family ritual and parental well-being. Master thesis, Baylor University. Retrieved from https://baylor-ir.tdl.org/handle/2104/9630

Nelson, S. K., Kushlev, K., \& Lyubomirsky, S. (2014). The pains and pleasures of parenting: When, why, and how is parenthood associated with more or less well-being? Psychological Bulletin, 140(3), 846-895. http://dx.doi.org/10.1037/a0035444

${ }^{*}$ Oduor, E., Neustaedter, C., Odom, W., Tang, A., Moallem, N., Tory, M., \& Irani, P. (2016). The frustrations and benefits of mobile device usage in the home when co-present with family members. Proceedings of the 2016 ACM Conference on Designing Interactive Systems, 1315-1327. https://doi.org/10.1145/2901790.2901809

*Palen, L., \& Hughes, A. (2007). When home base is not a place: Parents' use of mobile telephones. Personal and Ubiquitous Computing, 11(5), 339-348. https://doi.org/10.1007/s00779-006-0078-3

${ }^{*}$ Radesky, J., Leung, C., Appugliese, D., Miller, A. L., Lumeng, J. C., \& Rosenblum, K. L. (2018). Maternal mental representations of the child and mobile phone use during parent-child mealtimes. Journal of Developmental and Behavioral Pediatrics: JDBP, 39(4), 310-317. https://doi.org/10.1097/DBP.0000000000000556

${ }^{\star}$ Radesky, J., Miller, A. L., Rosenblum, K. L., Appugliese, D., Kaciroti, N., \& Lumeng, J. C. (2015). Maternal mobile device use during a structured parent-child interaction task. Academic Pediatrics, 15(2), 238-244. https://doi.org/10.1016/j.acap.2014.10.001
Rudi, J., Dworkin, J., Walker, S., \& Doty, J. (2015). Parents' use of information and communications technologies for family communication: differences by age of children. Information, Communication \& Society, 18(1), 78-93. https://doi.org/10.1080/136911 8X.2014.934390

Saferinternet (2019). Digitaler Zeitstress bei Jugendlichen. Retrieved from https://www.saferinternet.at/studien/

Stern, M. J., \& Messer, C. (2009). How family members stay in touch: A quantitative investigation of core family networks. Marriage \& Family Review, 45(6-8), 654-676. https://doi.org/10.1080/01494 920903224236

${ }^{*}$ Stockdale, L. A., Coyne, S. M., \& Padilla-Walker, L. M. (2018). Parent and child technoference and socioemotional behavioral outcomes: A nationally representative study of 10 - to 20 -year-old adolescents. Computers in Human Behavior, 88, 219-226. https://doi. org/10.1016/j.chb.2018.06.034

${ }^{*}$ Stupica, B. (2016). Rounding the bases with a secure base. Attachment \& Human Development, 18(4), 373-390. https://doi.org/10.1080/14 616734.2016.1170052

"Ventura, A. K., \& Teitelbaum, S. (2017). Maternal distraction during breast- and bottle feeding among WIC and non-WIC mothers. Journal of Nutrition Education and Behavior, 49(7), S169-S176.e1. https://doi.org/10.1016/j.jneb.2017.04.004

Zimmer-Gembeck, M. J., Webb, H. J., Pepping, C. A., Swan, K., Merlo, O., Skinner, E. A., ... Dunbar, M. (2017). Review: Is parent-child attachment a correlate of children's emotion regulation and coping? International Journal of Behavioral Development, 41(1), 74-93. https://doi.org/10.1177/0165025415618276

Zimmermann, P., Mohr, C., \& Spangler, G. (2009). Genetic and attachment influences on adolescents' regulation of autonomy and aggressiveness. Journal of Child Psychology and Psychiatry, 50(11), 13391347. https://doi.org/10.1111/j.1469-7610.2009.02158.

\section{${ }^{*}$ Corresponding author}

Martina Zemp, University of Vienna, Department of Clinical and Health Psychology, Renngasse 6-8, 1010 Vienna, Austria.

Email: martina.zemp@univie.ac.at, Phone: +43-1-4277-47284

\section{Funding information}

This research did not receive any grant from funding agencies in the public, commercial, or not-for-profit sectors. We confirm that there are no conflicts of interest which might have influenced our work.

\section{Author contributions}

BK conducted the systematic literature search, screened studies for eligibility, coded the studies, and wrote the manuscript.

MZ supported the literature search, supervised screening and coding of studies, and wrote the manuscript.

\section{Acknowledgements}

We thank Xenia Ziegler for finalizing and formatting our tables. 


\section{Electronic supplements}

Table 1. Keywords for Literature Research

\begin{tabular}{|c|c|c|c|}
\hline Parent terms & Child terms & Smart device terms & Parent-child interaction terms \\
\hline $\begin{array}{l}\operatorname{Parent}^{\star}(s), \text { parental, } \operatorname{mother}^{\star}(s), \\
\text { maternal, } \operatorname{mom}^{\star}(s), \operatorname{father}^{\star}(s), \\
\text { paternal, } \operatorname{dad}^{\star}(s)\end{array}$ & $\begin{array}{l}\text { Child, children (child*), } \\
\text { adolescents }\end{array}$ & $\begin{array}{l}\text { Smartphone, smart phone, } \\
\text { smart device, mobile phone, } \\
\text { tablet, laptop, screen time, } \\
\text { portable screen }\end{array}$ & $\begin{array}{l}\text { Interaction, relationship } \\
\text { (quality), (quality) time, } \\
\text { sensitivity, communication, } \\
\text { responsivity, responsiveness, } \\
\text { conflict }\end{array}$ \\
\hline
\end{tabular}

Table 2. Quality Assessment of Included Studies

\begin{tabular}{|c|c|c|c|c|c|c|c|c|}
\hline \multirow[t]{2}{*}{ Author(s) } & \multirow{2}{*}{$\begin{array}{l}\text { Category }{ }^{\mathrm{a}} \text { for } \\
\text { Study Design }\end{array}$} & \multicolumn{7}{|c|}{ Quality Criteriab $^{b}$} \\
\hline & & S1 & S2 & 1 & 2 & 3 & 4 & 5 \\
\hline Abels et al. (2018) & 4 & + & + & + & + & + & + & + \\
\hline Ante-Contreras (2016) & 4 & + & + & + & + & + & - & ? \\
\hline Blackmann (2015) & 4 & + & + & + & + & + & + & + \\
\hline Chen, Zhou, \& Han (2017) & 1 & + & + & + & $?$ & + & - & ? \\
\hline Golen \& Ventura (2015) & 5 & + & + & + & + & + & $?$ & + \\
\hline Hiniker, Sobel, Suh, Sung, Lee, \& Kientz (2015) & 5 & + & + & + & + & $?$ & + & ? \\
\hline Johnson (2017) & 1 & + & + & + & + & $?$ & $?$ & + \\
\hline Kellersohn (2018) & 4 & + & + & + & $?$ & + & + & ? \\
\hline Khourochvili (2017) & 4 & + & + & - & - & + & + & + \\
\hline Kushlev \& Dunn (2019; Study 1) & 3 & $?$ & + & + & $?$ & + & + & + \\
\hline Kushlev \& Dunn (2019; Study 2) & 4 & + & + & + & + & $?$ & $?$ & + \\
\hline Lanette (2018) & 5 & + & + & + & + & $?$ & - & ? \\
\hline Mangan et al. (2017) & 5 & + & + & + & + & + & $?$ & + \\
\hline Myruski et al. (2018) & 3 & + & + & + & + & + & $?$ & + \\
\hline Nelson (2016) & 4 & + & + & + & $?$ & $?$ & - & + \\
\hline Oduor et al. (2016) & 5 & + & + & + & + & $?$ & - & + \\
\hline Palen \& Hughes (2007) & 5 & + & + & + & $?$ & $?$ & + & + \\
\hline Radesky et al. (2018) & 4 & + & + & $?$ & + & + & + & + \\
\hline Radesky et al. (2015) & 4 & + & + & + & $?$ & $?$ & + & + \\
\hline Stockdale et al. (2018) & 4 & + & + & + & + & + & + & + \\
\hline Stupica et al. (2016) & 4 & + & + & + & + & + & $?$ & + \\
\hline Ventura \& Teitelbaum (2017) & 5 & + & + & + & + & + & + & + \\
\hline
\end{tabular}

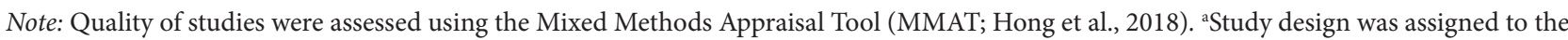
MMAT design categories: 1 = Qualitative; 2 = Quantitative randomized controlled trials; 3 = Quantitative non-randomized; $4=$ Quantitative descriptive; 5 = Mixed methods ${ }^{\text {b}}$ Two general quality criteria (S1 and S2) and five design-specific quality criteria ( 1 to 5 ) were assessed: according to the MMAT; + = criterion is met; - = criterion is not met; ? = criterion is not assessable. 


\begin{tabular}{|c|c|c|c|c|}
\hline 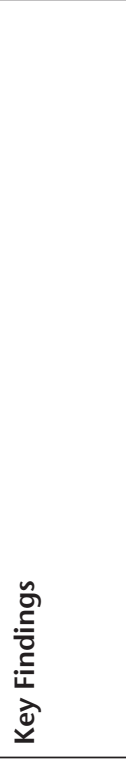 & 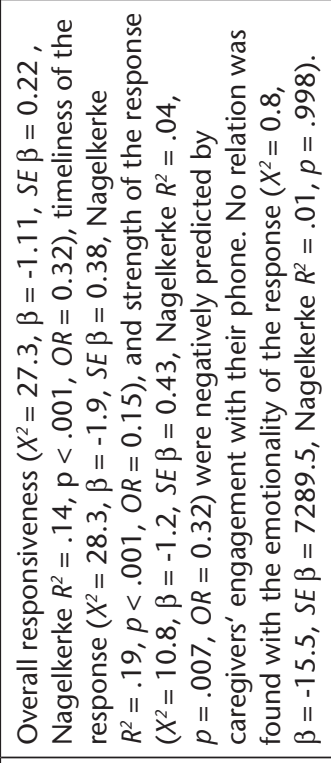 & 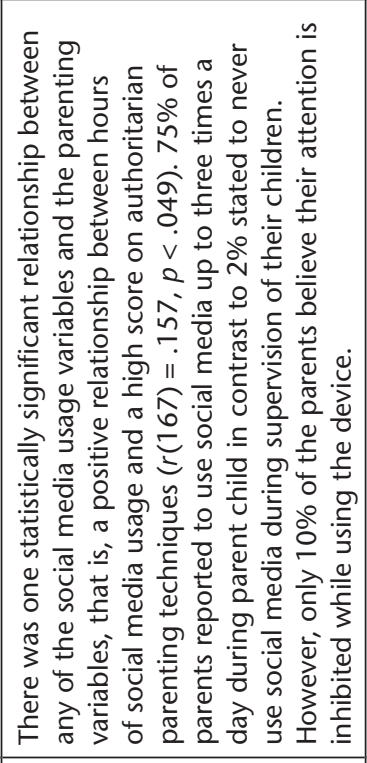 & 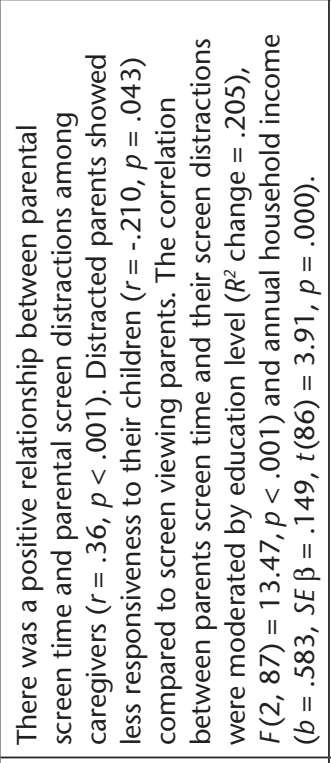 & 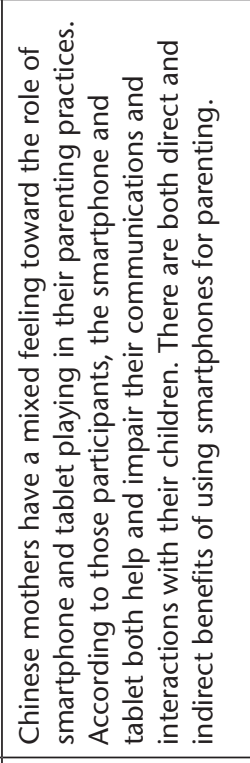 \\
\hline 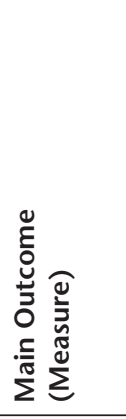 & 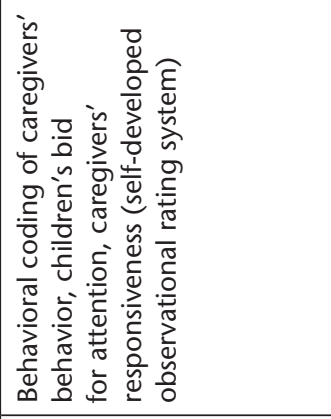 & 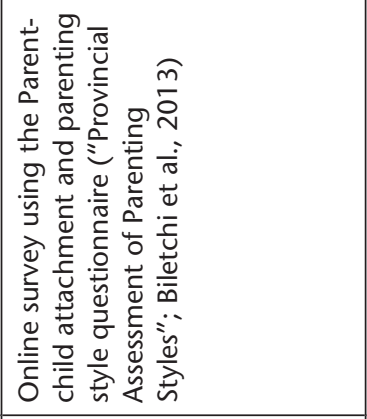 & 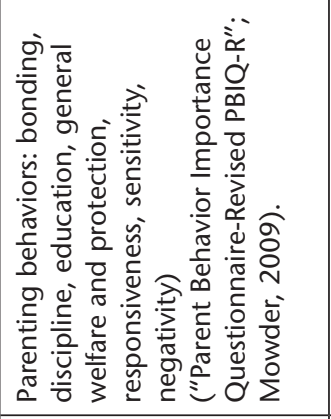 & 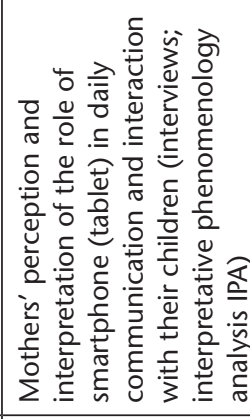 \\
\hline 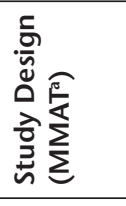 & 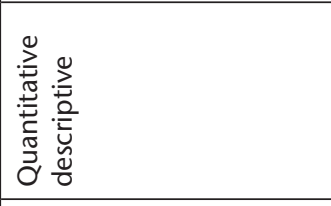 & 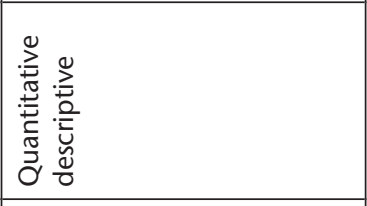 & 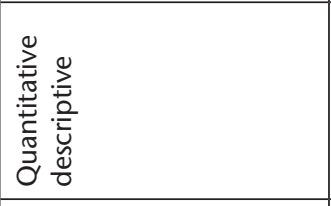 & 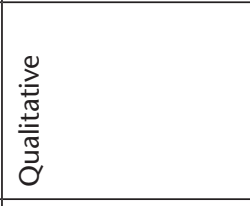 \\
\hline 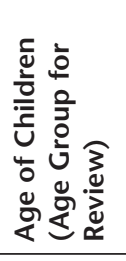 & 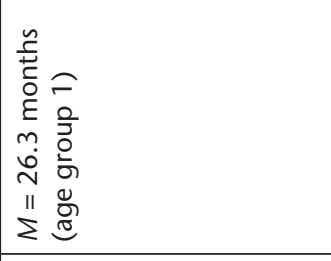 & 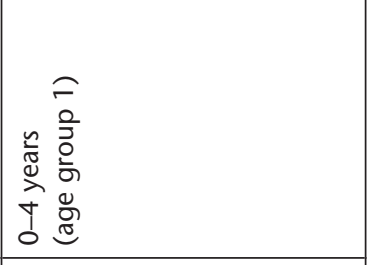 & 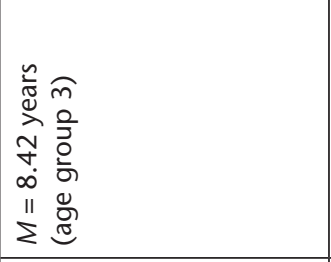 & 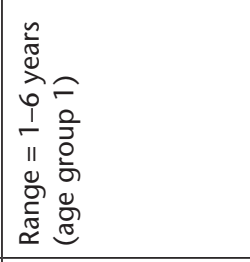 \\
\hline $\begin{array}{l}\widehat{z} \\
\frac{0}{0} \\
\frac{\tilde{\varepsilon}}{5} \\
\end{array}$ & 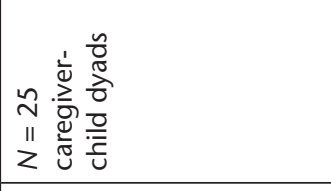 & 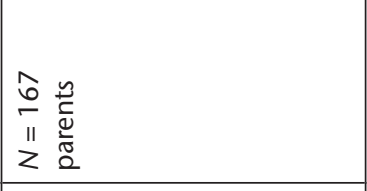 & 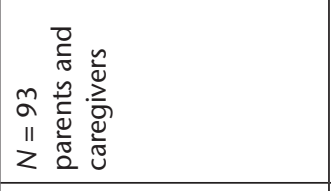 & 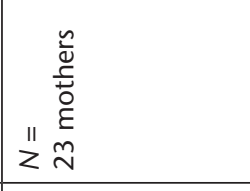 \\
\hline 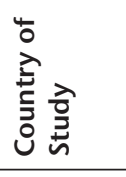 & 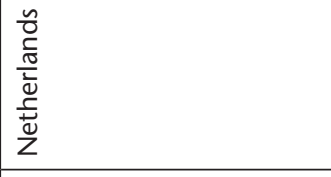 & 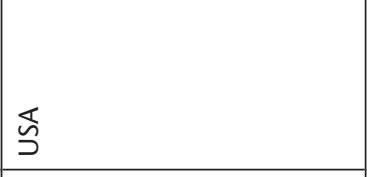 & ऽิ & 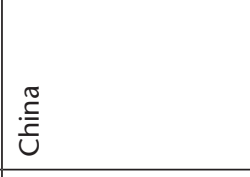 \\
\hline 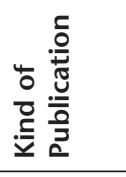 & 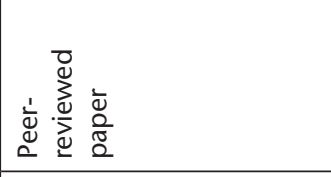 & $\begin{array}{l}\frac{n}{\mathscr{Q}} \\
\stackrel{5}{F}\end{array}$ & $\begin{array}{l}\frac{n}{\mathscr{U}} \\
\stackrel{F}{F}\end{array}$ & 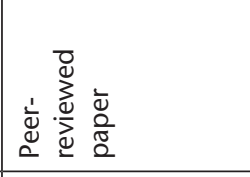 \\
\hline 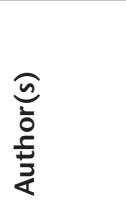 & 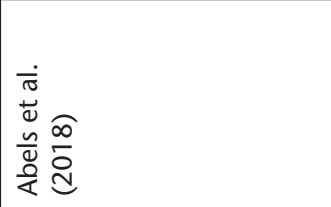 & 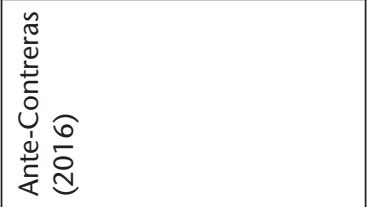 & 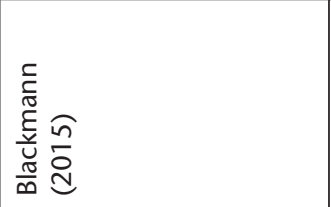 & 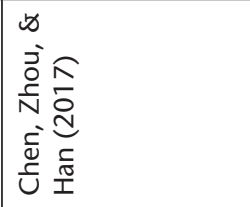 \\
\hline
\end{tabular}




\begin{tabular}{|c|c|c|c|}
\hline 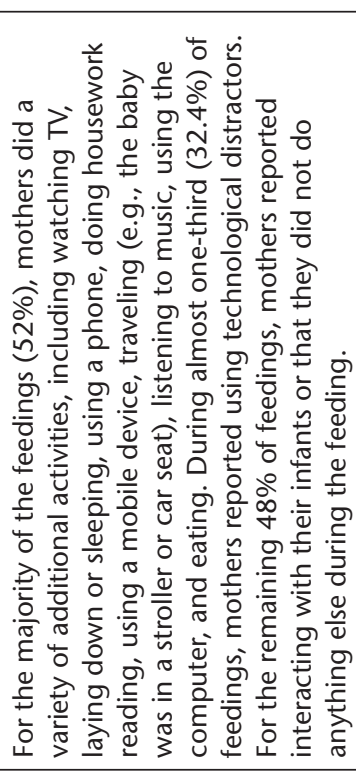 & 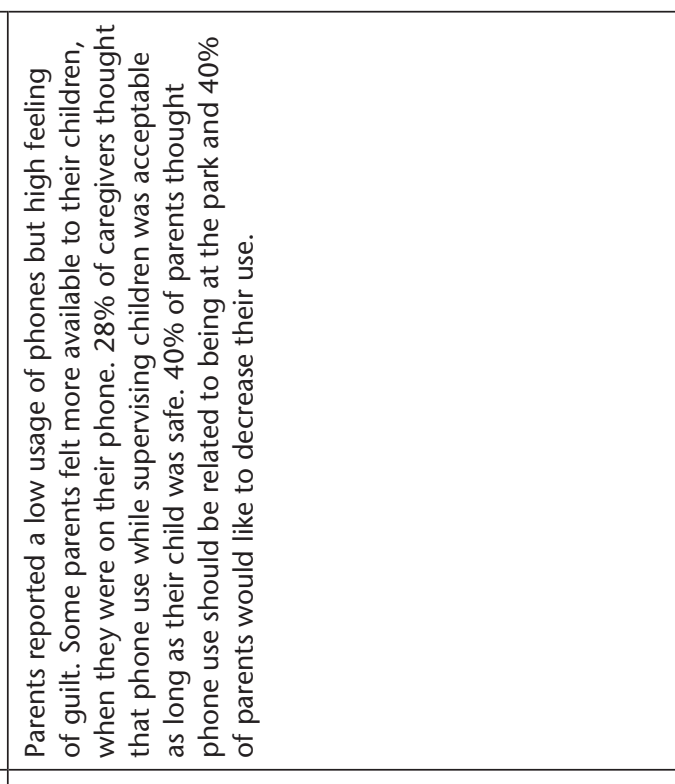 & 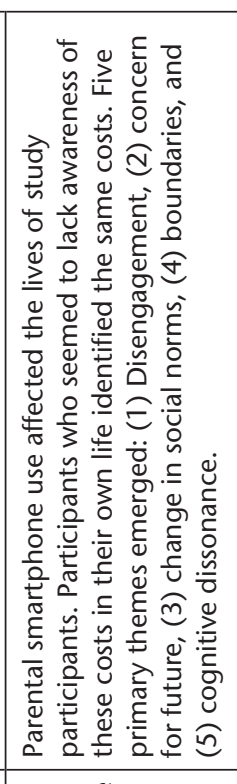 & 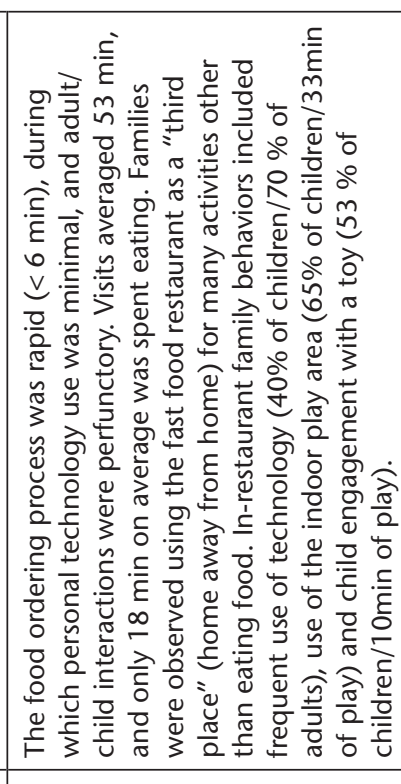 \\
\hline 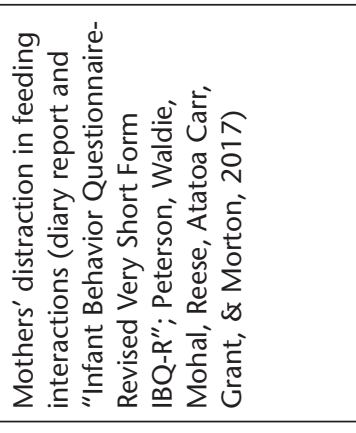 & 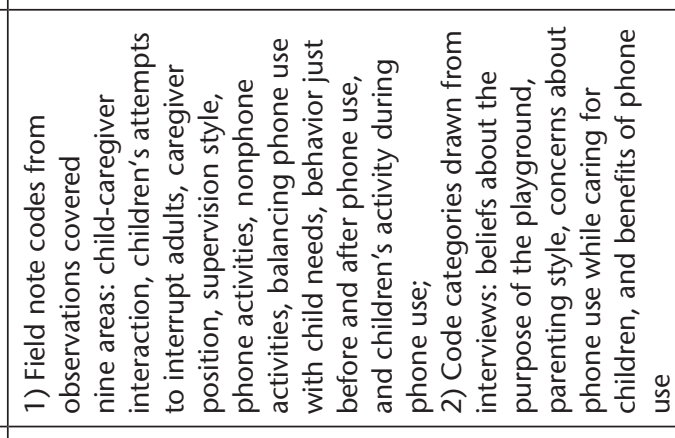 & 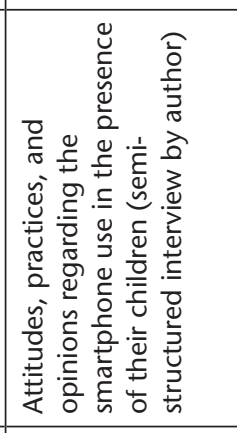 & 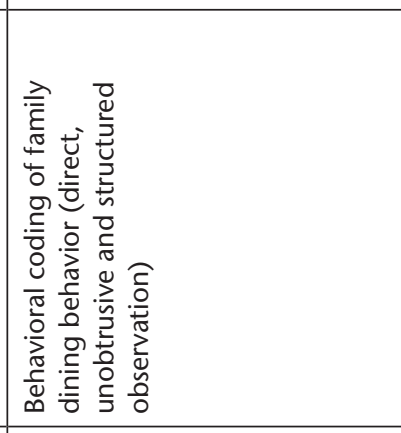 \\
\hline 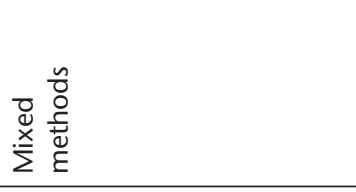 & 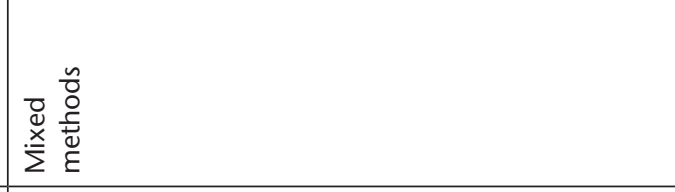 & 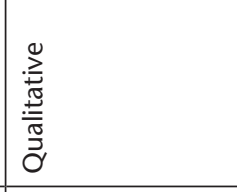 & 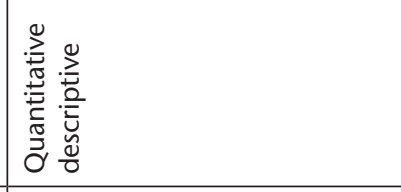 \\
\hline 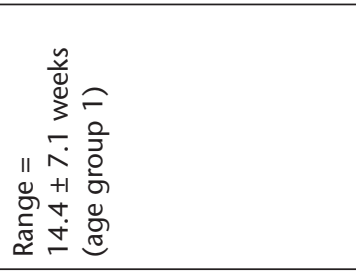 & 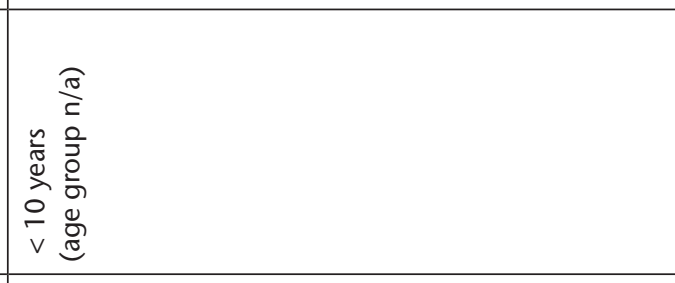 & 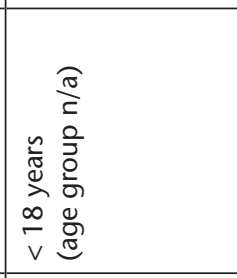 & 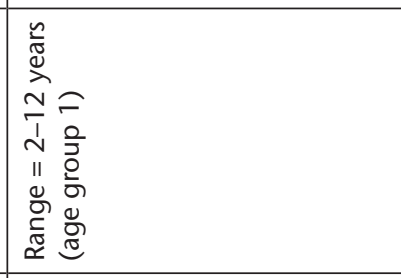 \\
\hline 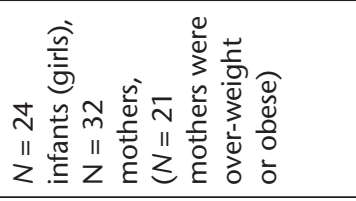 & 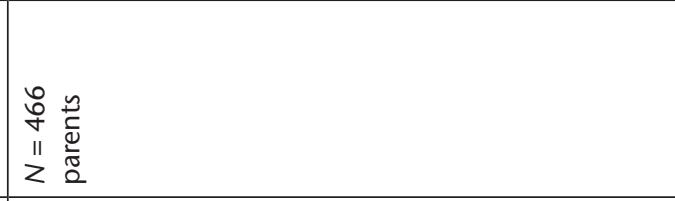 & 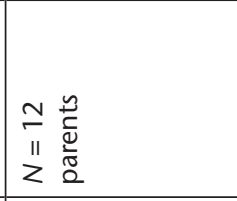 & 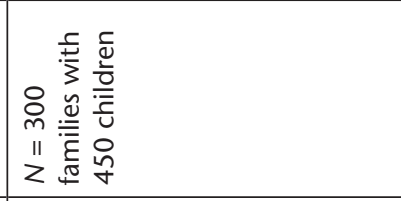 \\
\hline 离 & 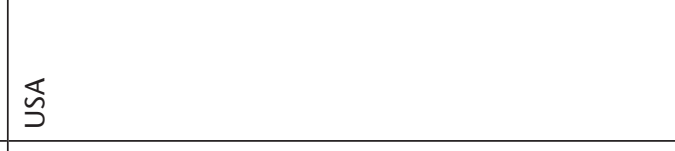 & 离 & 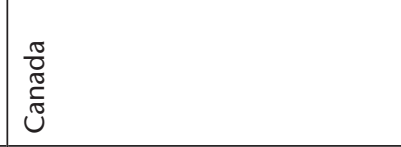 \\
\hline 离 & 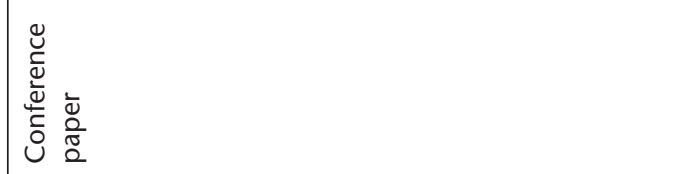 & 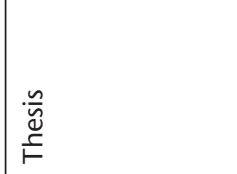 & 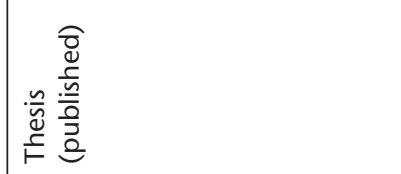 \\
\hline 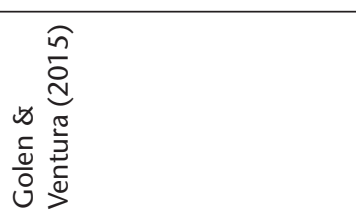 & 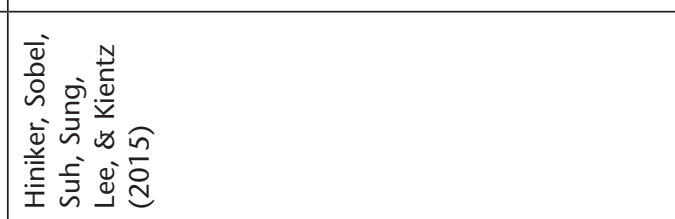 & 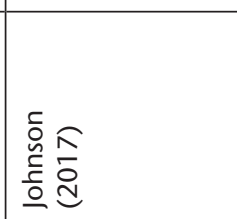 & 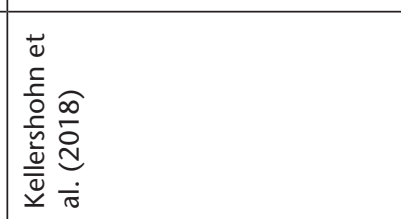 \\
\hline
\end{tabular}




\begin{tabular}{|c|c|c|c|}
\hline 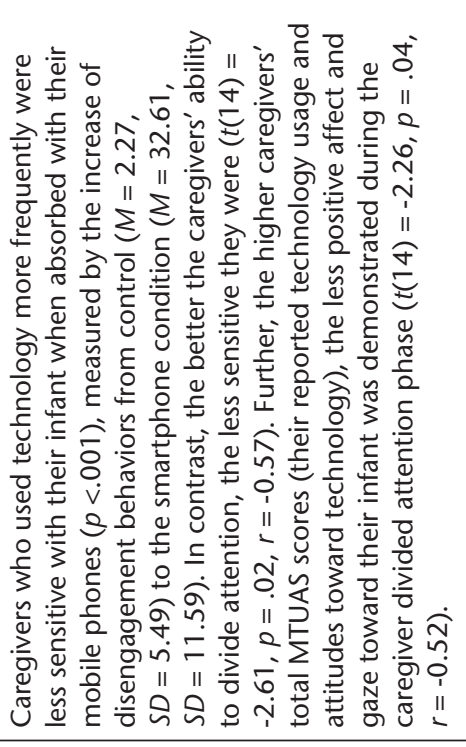 & 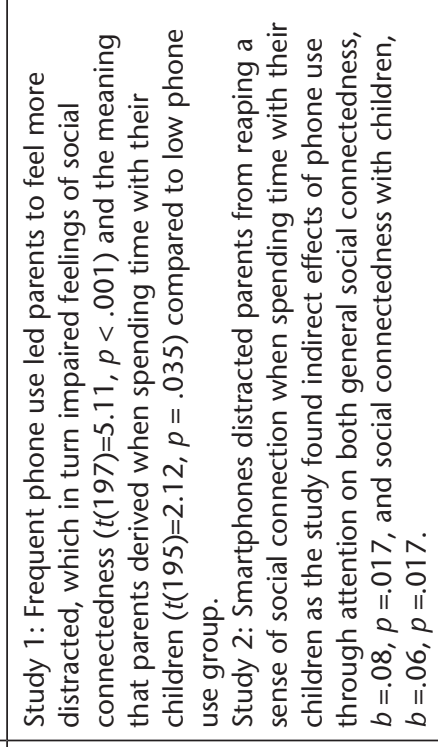 & 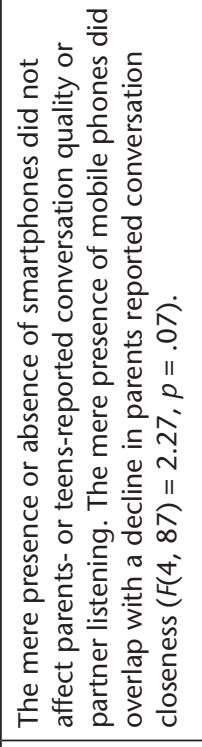 & 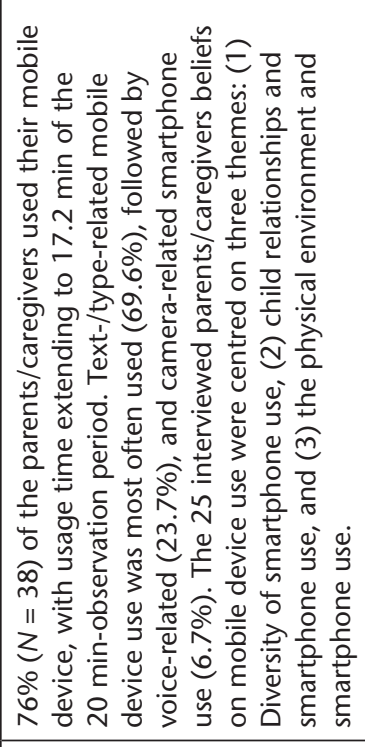 \\
\hline 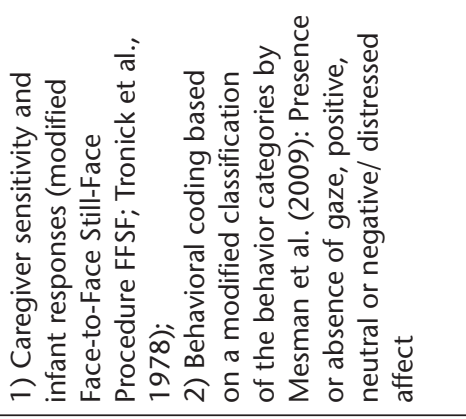 & 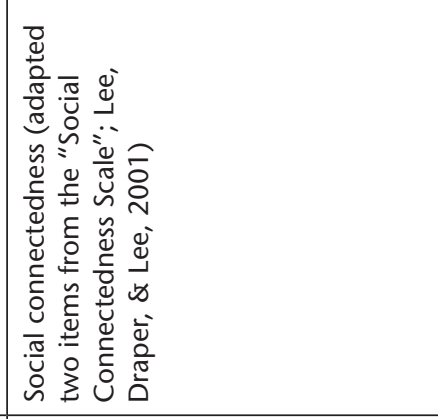 & 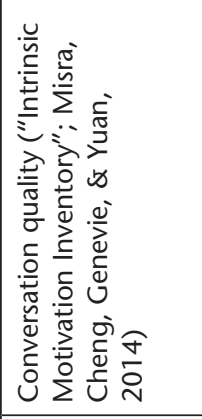 & 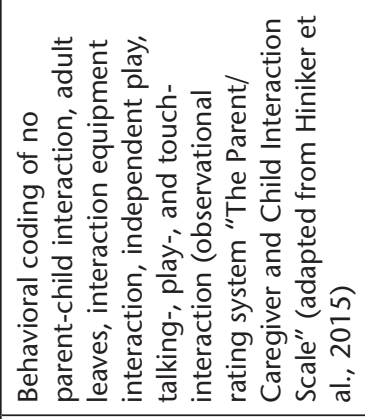 \\
\hline 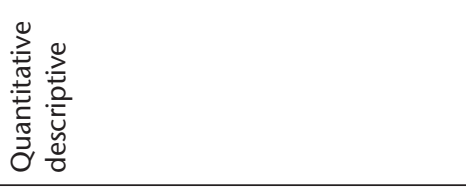 & 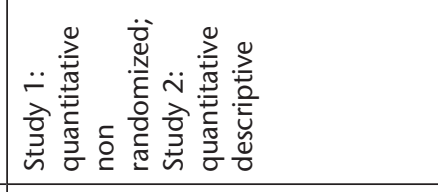 & 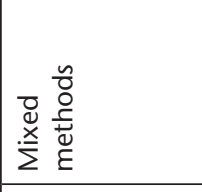 & 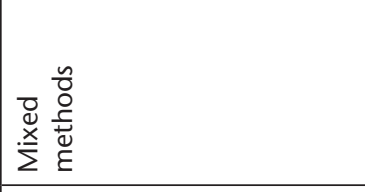 \\
\hline 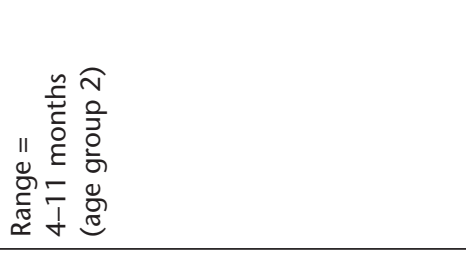 & 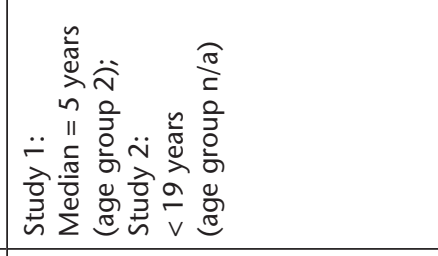 & 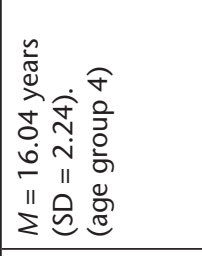 & 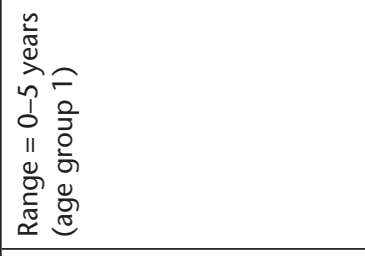 \\
\hline 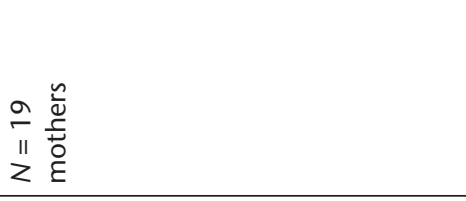 & 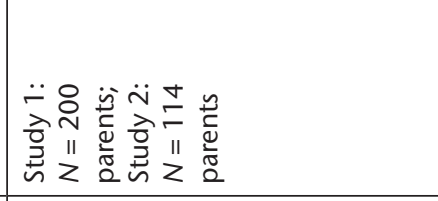 & 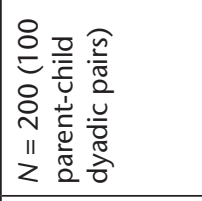 & 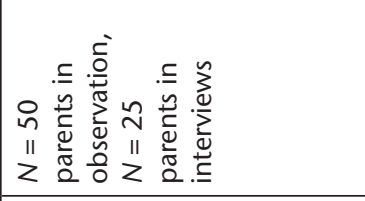 \\
\hline 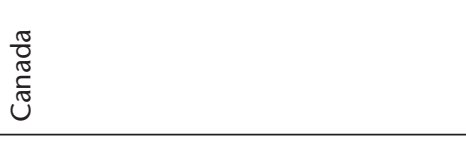 & 离 & 离 & 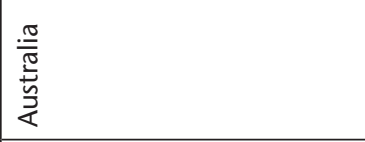 \\
\hline 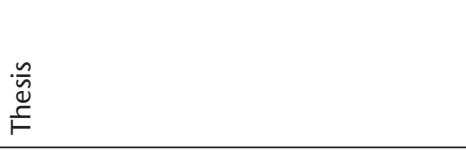 & 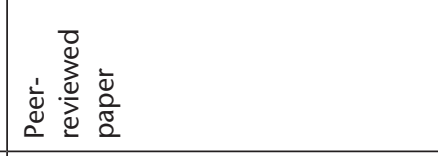 & 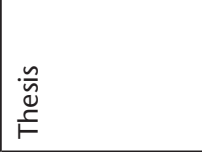 & 离 \\
\hline 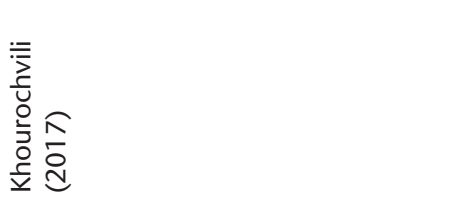 & 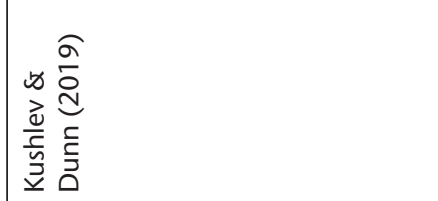 & 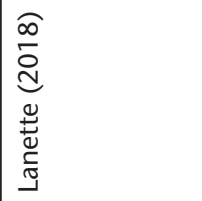 & 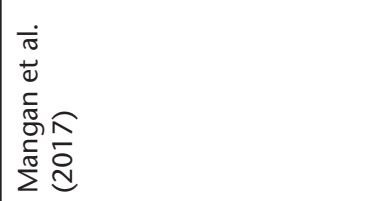 \\
\hline
\end{tabular}




\begin{tabular}{|c|c|c|c|c|}
\hline 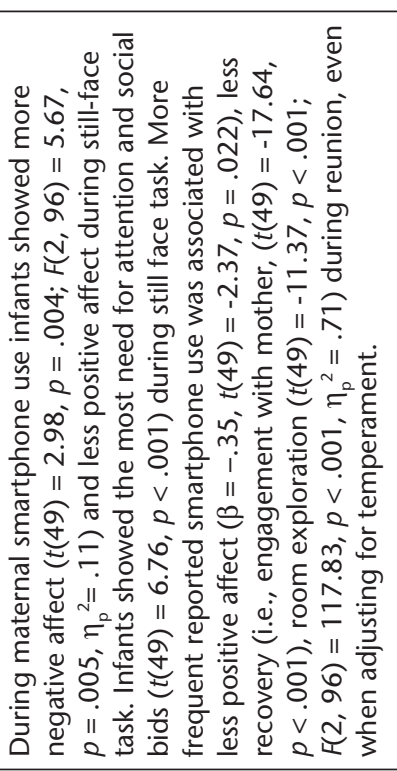 & 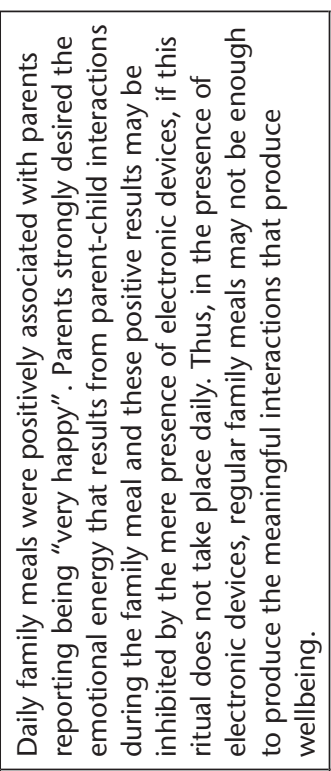 & 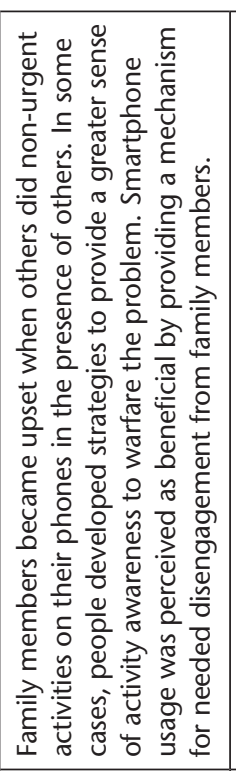 & 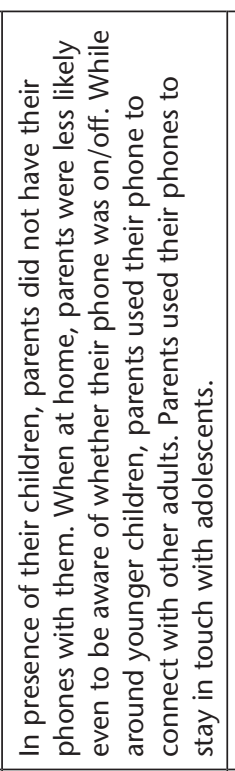 & 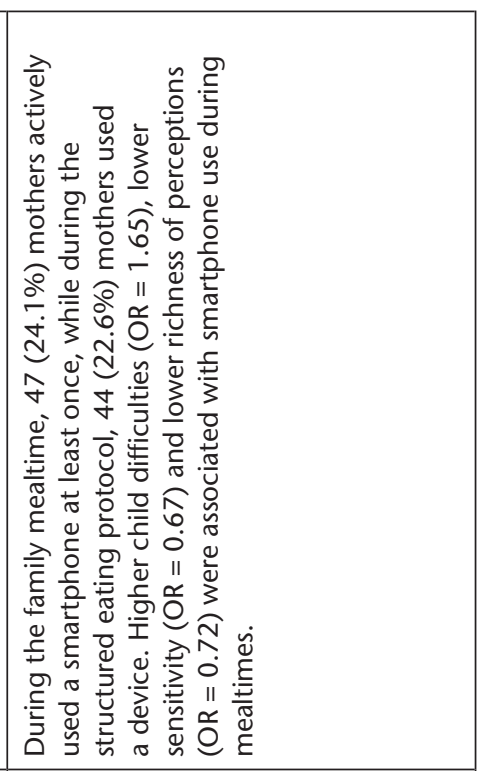 \\
\hline 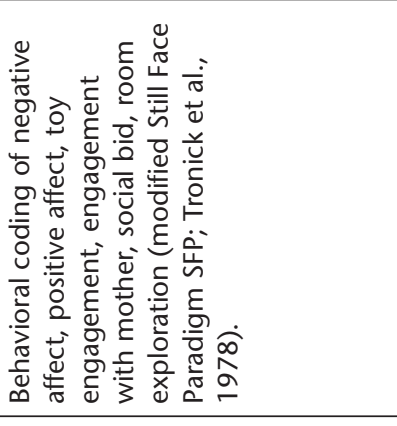 & 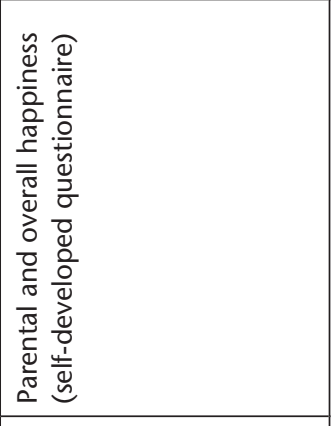 & 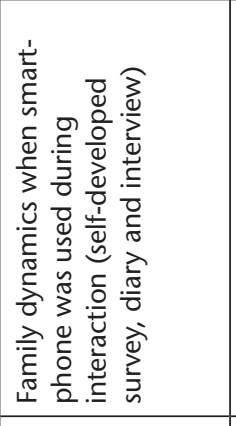 & 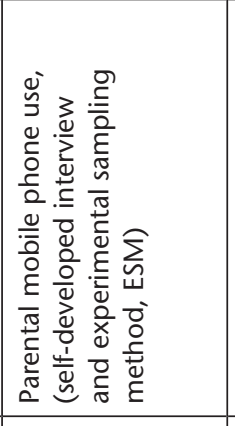 & 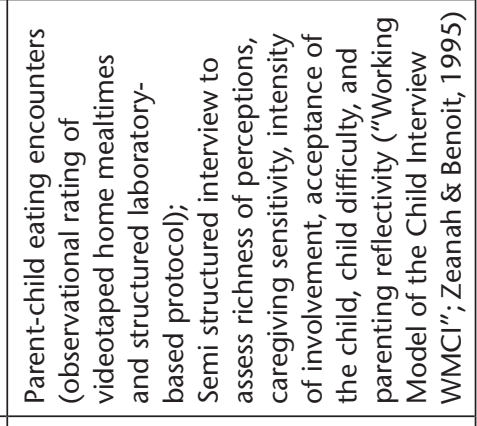 \\
\hline 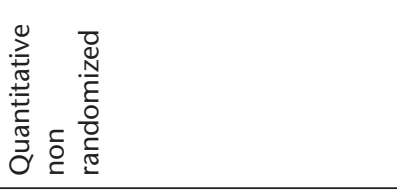 & 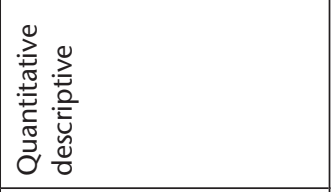 & 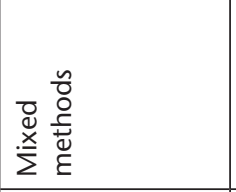 & 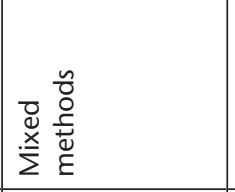 & 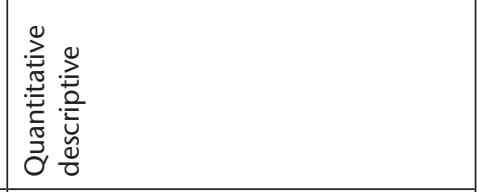 \\
\hline 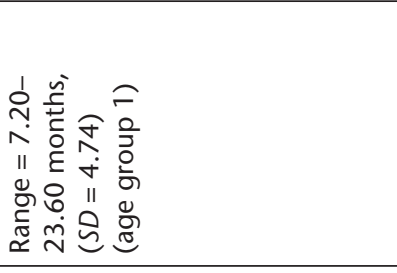 & 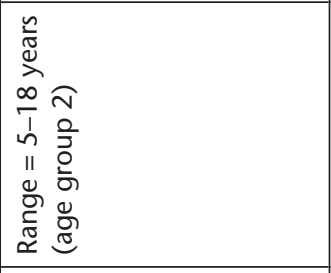 & 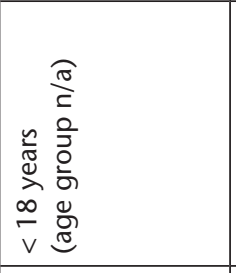 & 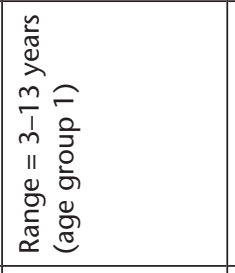 & 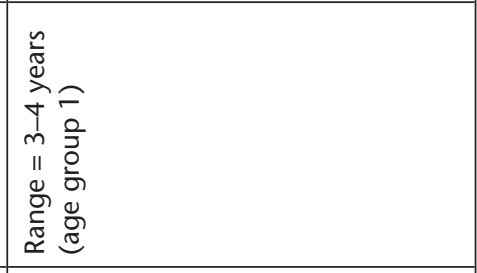 \\
\hline 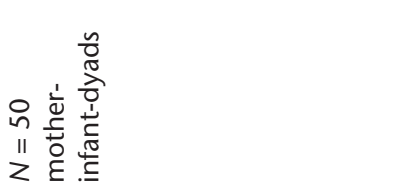 & 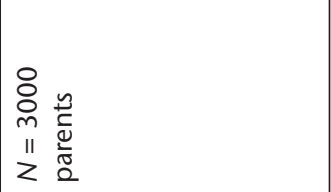 & $\begin{array}{l}\stackrel{N}{11} \\
\text { Z }\end{array}$ & 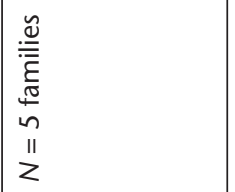 & 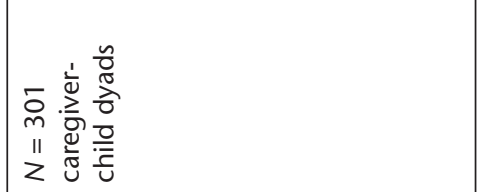 \\
\hline 芯 & 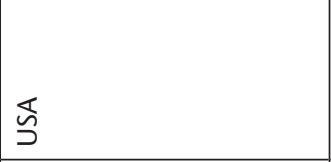 & 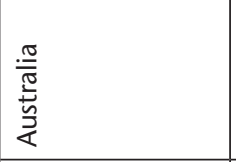 & 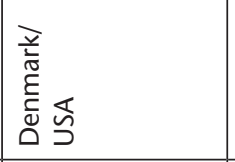 & 岕 \\
\hline 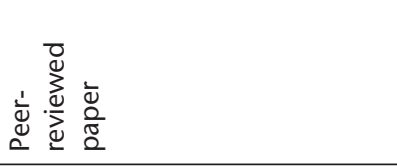 & $\begin{array}{l}\stackrel{.}{\tilde{Q}} \\
\stackrel{F}{F}\end{array}$ & 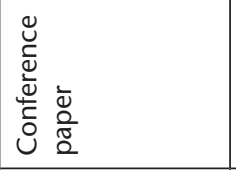 & 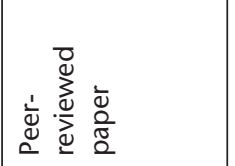 & 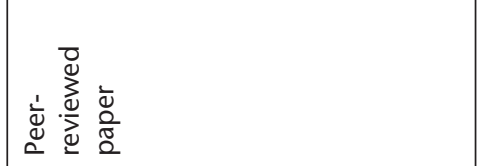 \\
\hline 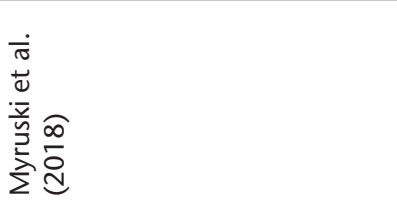 & 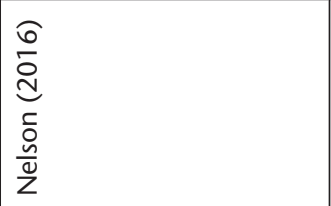 & $\begin{array}{l}\bar{\pi} \\
\stackrel{0}{0} \\
\frac{0}{0} \\
\overline{2} \\
0 \\
0\end{array}$ & 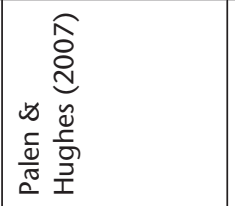 & 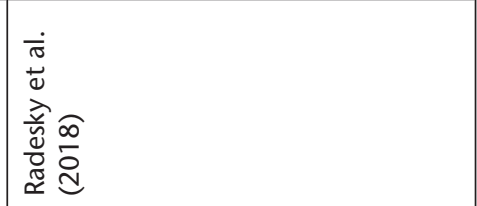 \\
\hline
\end{tabular}




\begin{tabular}{|c|c|c|c|}
\hline 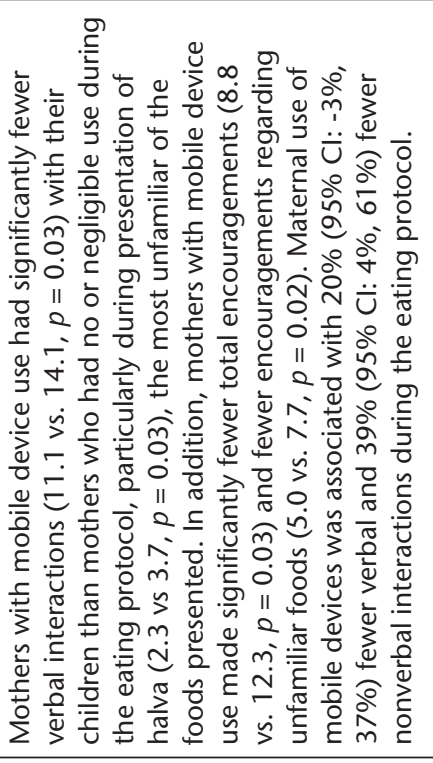 & 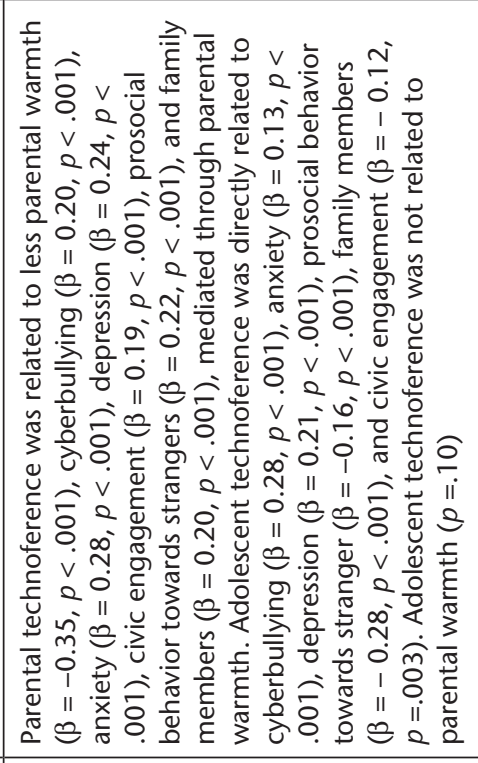 & 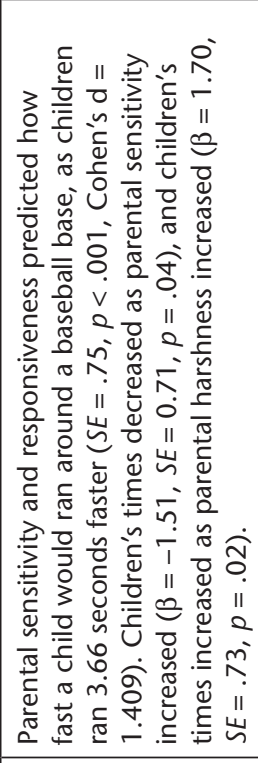 & 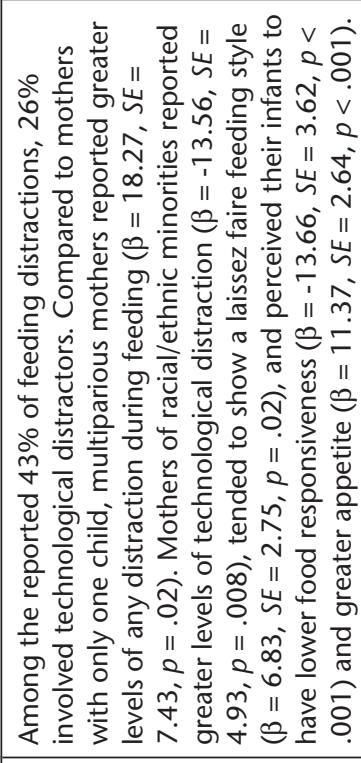 \\
\hline 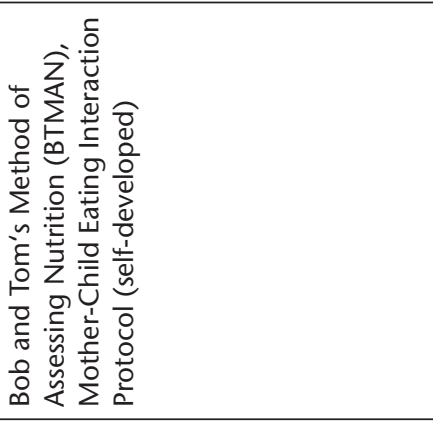 & 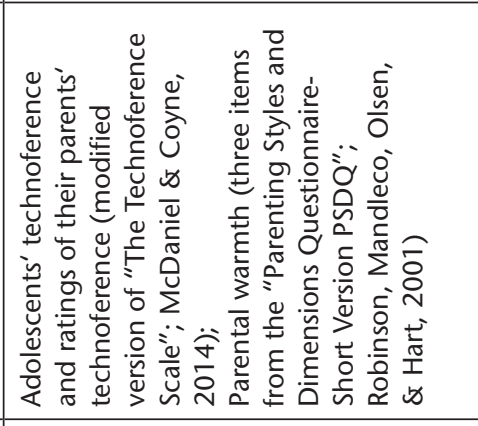 & 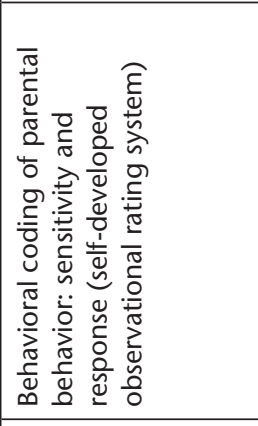 & 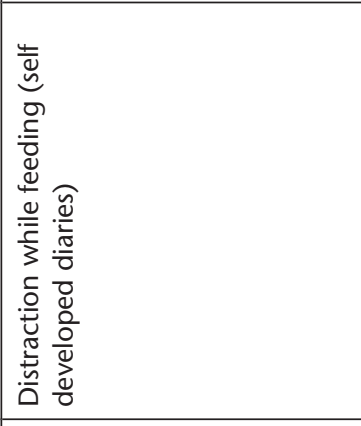 \\
\hline 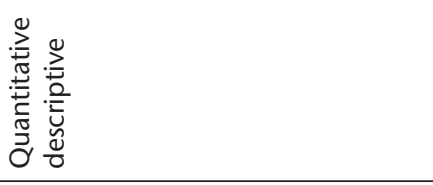 & 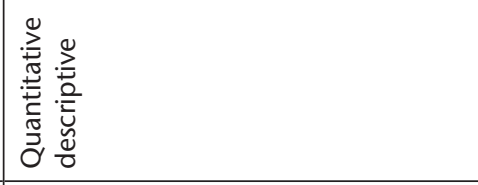 & 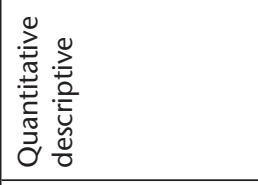 & 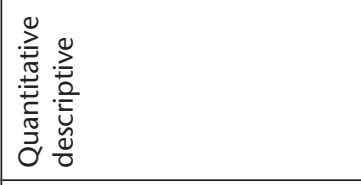 \\
\hline 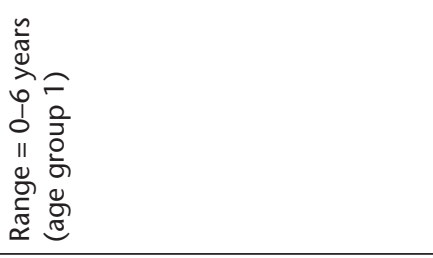 & 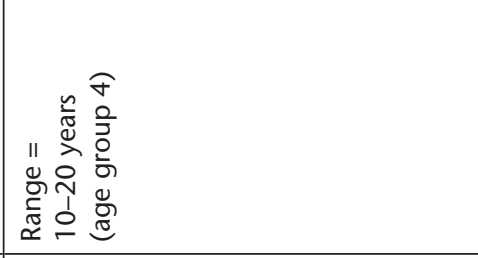 & 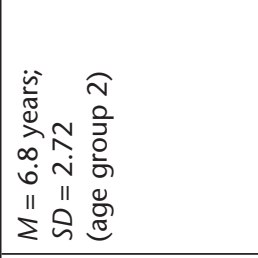 & 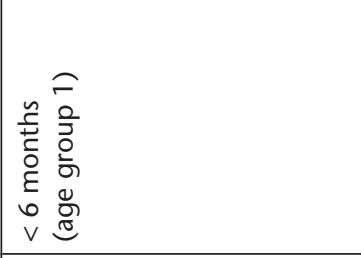 \\
\hline 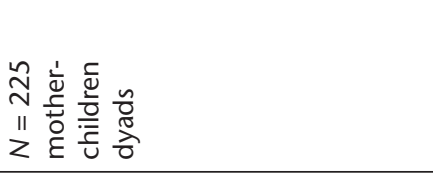 & 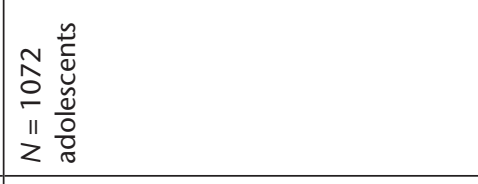 & 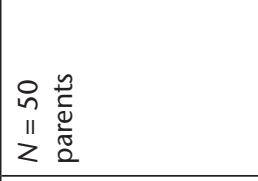 & 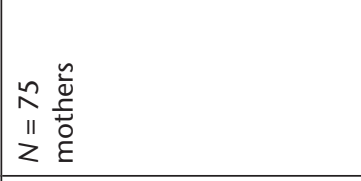 \\
\hline 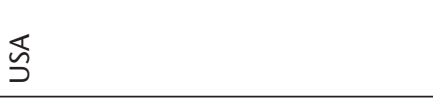 & 芯 & 芯 & 芯 \\
\hline 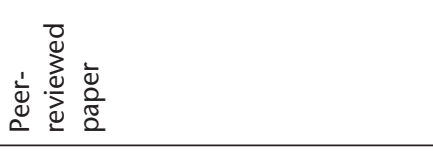 & 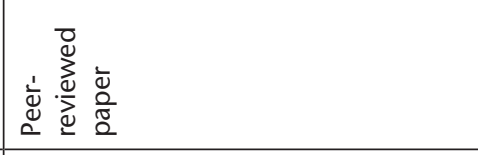 & 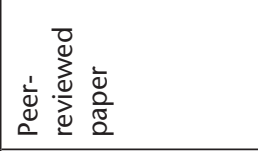 & 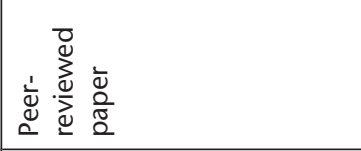 \\
\hline 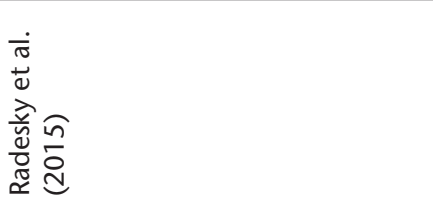 & 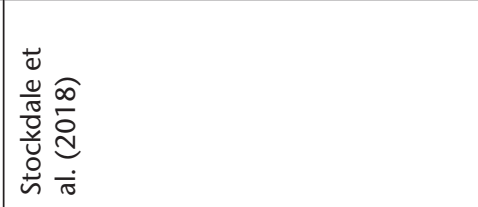 & 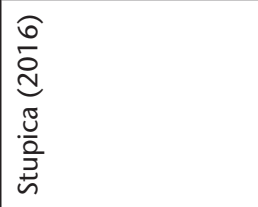 & 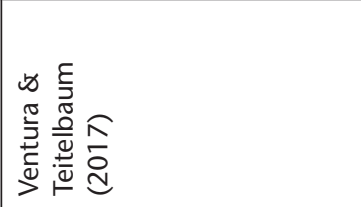 \\
\hline
\end{tabular}

